\title{
An Examination of the Leadership Practices of University Presidents of Land-Grant Universities in the United States
}

Wafa M. Aldighrir

West Virginia University

Follow this and additional works at: https://researchrepository.wvu.edu/etd

\section{Recommended Citation}

Aldighrir, Wafa M., "An Examination of the Leadership Practices of University Presidents of Land-Grant Universities in the United States" (2013). Graduate Theses, Dissertations, and Problem Reports. 273.

https://researchrepository.wvu.edu/etd/273

This Dissertation is protected by copyright and/or related rights. It has been brought to you by the The Research Repository @ WVU with permission from the rights-holder(s). You are free to use this Dissertation in any way that is permitted by the copyright and related rights legislation that applies to your use. For other uses you must obtain permission from the rights-holder(s) directly, unless additional rights are indicated by a Creative Commons license in the record and/ or on the work itself. This Dissertation has been accepted for inclusion in WVU Graduate Theses, Dissertations, and Problem Reports collection by an authorized administrator of The Research Repository @ WVU.

For more information, please contact researchrepository@mail.wvu.edu. 
An Examination of the Leadership Practices of University Presidents of Land-Grant Universities in the United States

\author{
Wafa M. Aldighrir \\ Dissertation submitted to the \\ College of Human Resources and Education \\ at West Virginia University \\ in partial fulfillment of the requirements for the degree of \\ Doctor of Education in \\ Educational Leadership Studies \\ Paul Chapman, Ph.D., Chair \\ Richard T. Walls, Ph.D. \\ Ernest Goeres, Ph.D. \\ DJ Hendricks, Ed.D. \\ Nancy Adams, Ph.D.
}

Department of Educational Leadership Studies

Morgantown, West Virginia

2013

Keywords: University Presidents, Land-Grant Universities, Kouzes and Posner, LPI. 


\begin{abstract}
A great deal of research has been done to understand leadership styles in different organizational settings. In this study, the researcher focused on the leadership practices of university presidents of land-grant universities (LGUs) in the United States. The study examined the leadership practices of presidents of land-grant universities as described by Kouzes and Posner (2002). Moreover, this study aimed to find whether a difference existed among university presidents in terms of leadership practices. Using a mixed research method, the researcher conducted an individual LPI self-survey and five interviews to answer the research questions. The findings indicate that university presidents engaged highly in all five leadership practices that were discussed by Kouzes and Posner (2002). University presidents understand the importance of each practice that impacts the quality of leadership as well as the organizational performance. Furthermore, the study indicated there is a difference in terms of leadership practices among university presidents. In sum, there was a unique pattern established among the presidents at land-grant universities related to leadership practices. First, the leadership practice of "Enabling Others to Act" is the main practice, although presidents could somehow not detach it from the concept of "Modeling the Way." Presidents discussed the importance of enabling others while they related to modeling the way or vice versa. The second part of the leadership model is that the leadership practices model a "process" in which all five practices work together to achieve the ultimate goal. This is how the presidents of land-grant universities described their leadership practices.
\end{abstract}




\section{Dedication}

I dedicate this work to my family, my beloved, Hadi Alyami; and my children, Lean, Lana, and Aleen. You have amazed me with your encouragement and patience throughout my entire educational process. I can only hope that I have set a good example for you all. 


\section{Acknowledgement}

Writing this dissertation was a monumental task in my life. It was challenging to conduct this study. My success in this journey is not only mine. Thanks to God for giving me the power to lead me along the way in every regard.

I wish to thank my husband, Hadi Alyami. This is one thing I owe to you. Without your loving, unwavering support, unbelievable tolerance, and your encouragement to complete my study, this work would never exist. Thanks very much for everything you have done for me to achieve this dream. You knew what this study meant to me, and you offered the environment that helped me succeed in my life. Thanks a lot to my three beautiful girls: Lean, Lana, and Aleen. I took my time to do my research, and I always apologized to them, hoping one day they will understand why. They always asked me when I was going to finish. I love you all.

I thank the members on my dissertation committee starting with the committee chair, Dr. Paul Chapman, the Interim Associate Dean of higher education administration. He believed in my ability to conduct this study, which gave me the motivation to do so. Dr. Chapman worked with me on a weekly basis to ensure that I produced the best work without giving me too much pressure to complete the research. Thanks, Dr. Chapman, for your support in this journey. I wish also to thank Dr. Ernest Goeres, Dr. Nancy Adams, Dr. DJ Hendricks, and Dr. Richard Walls for their professional support of the dissertation.

I would also like to thank the university presidents who completed the surveys and did the interview for this study. Thanks also to Duseyland Daycare and their family for taking care of my kids for seven years. I love you, and I appreciate your lovely care of my children. I will never ever find a place like Duseyland Daycare. Last but not least, I thank my family for their 
forbearance and willingness to ask me always, "When will you be done with your study? You spend your life between books" Thanks for asking, and I love you, too.

Here I am, finally. I am getting to the end of this road, but learning will never ever be done. 
Table of Contents

Abstract $\quad$ ii

$\begin{array}{ll}\text { Dedication } & \text { iii }\end{array}$

Acknowledgement $\quad$ iv

Table of Contents

Appendices

List of Tables $\quad$ X

List of Figures $\quad$ xii

Chapter One 1

Introduction $\quad 1$

Background of the Study $\quad 5$

The Problem Statement $\quad 8$

The Purpose of the Study 11

$\begin{array}{ll}\text { Research Questions } & 12\end{array}$

The Professional Significance of the Study $\quad 12$

Limitations of the Study 13

Organization of the Study $\quad 13$

Definition of Key Terms 14

$\begin{array}{ll}\text { Chapter Two } & 16\end{array}$

$\begin{array}{ll}\text { Literature Review } & 16\end{array}$

The Conceptual Foundation of Leadership 16

$\begin{array}{ll}\text { Five Principles of Leadership } & 17\end{array}$

Practice one: Modeling the way. 19 
Practice two: Inspiring a shared vision.

Practice three: Challenging the process.

Practice four: Enabling others to act.

Practice five: Encouraging the heart.

Important Laws that Shaped the Land-Grant University

Morrill Act of 1862

Morrill Act of 1890

An Overview of the Role of Presidents in HEIs

Previous Research on the Role of University Presidents

Previous Studies Using the Leadership Practices Inventory

Summary

Chapter Three

Methodology

Design of the Study

The Interview Questions

Participants of the Study

Instrumentation

Researcher as an Instrument in Interviews

Data Collection

Data Analysis

Anonymity and Confidentiality $\quad 66$

$\begin{array}{ll}\text { Chapter Four } & 67\end{array}$

Results 
Question one answer

Practice one: Enabling others to act. 71

$\begin{array}{ll}\text { Practice two: Modeling the way. } & 73\end{array}$

$\begin{array}{ll}\text { Practice three: Inspiring a shared vision. } & 76\end{array}$

$\begin{array}{ll}\text { Practice four: Challenging the process. } & 79\end{array}$

Practice five: Encouraging the heart $\quad 82$

$\begin{array}{ll}\text { Question two answer } & 85\end{array}$

$\begin{array}{ll}\text { Question three answer } & 88\end{array}$

$\begin{array}{ll}\text { Category one: Modeling the way. } & 91\end{array}$

Category two: Inspiring a shared vision. 95

Category three: Challenging the process. 97

$\begin{array}{ll}\text { Category four: Enabling others to act. } & 100\end{array}$

$\begin{array}{ll}\text { Category five: Encouraging the heart. } & 103\end{array}$

$\begin{array}{ll}\text { Chapter 5. Discussion, Conclusion, and Implications } & 109\end{array}$

Section one: The Leadership Practices of Presidents at Land-Grant

Universities as Reported in the LPI-Self Surveys and Interviews 109

Section Two: Leadership Practices Model of University

Presidents at Land-grant Universities $\quad 119$

$\begin{array}{ll}\text { Implications from the Study } & 124\end{array}$

$\begin{array}{ll}\text { References } & 128\end{array}$ 
Appendices

Appendix A. A List of All Land-Grant Universities

Appendix B. Leadership Practices Inventory Individual Survey

Appendix C. President's Cover Letter

Appendix D. President's first reminder

147

Appendix E. President's second reminder

Appendix F. Interview Request (First Email)

Appendix J. Interview Request (Fellow-up Email)

Appendix H. Kouzes and Posner Leadership Profile Inventory Permission 


\section{List of Tables}

Table 3.1 LPI Self-Survey Version: Means and Standard Deviations

Table 3.2 The Leadership Practices Inventory: Percentile Ranking

Table 3.3 Internal Reliability (Cronbach's alpha) for Self-Version

Table 4.1. Rank-Ordered Means and Standard Deviation for

the Leadership Practices Inventory

Table 4.2. University Presidents' Mean Leadership Practices Inventory

Ratings for Statements Related to Enabling Others to Act

Table 4.3. Frequency Counts and Percentages of Enabling Others to Act

Table 4.4. University Presidents' Mean Leadership Practices Inventory

Ratings for Statements Related to Modeling the Way

Table 4.5. Frequency Counts and Percentages Modeling the Way

Table 4.6. University Presidents' Mean Leadership Practices Inventory

Ratings for Statements Related to Inspiring a Shared Vision

Table 4.7. Frequency Counts and Percentages of Inspiring a Shared Vision

Table 4.8. University Presidents' Mean Leadership Practices Inventory

Ratings for Statements Related to Challenging the Process

Table 4.9. Frequency Counts and Percentages of Challenging the Process

Table 4.10. University Presidents' Mean Leadership Practices Inventory

Ratings for Statements Related to Encouraging the Heart

Table 4.11. Frequency Counts and Percentages of Encouraging the Heart

Table 4.12. Multivariate Tests (SPSS)

Table 4.13. The Mauchly's Test of Sphericity 
Table 4.14. The Pairwise Comparisons among the Five Leadership

Practices as Described by the University Presidents 


\section{List of Figures}

Figure 5.1. Leadership Practices Model of Presidents of Land-Grant Universities ............123 


\section{Chapter One}

\section{Introduction}

Leadership is an attribute, influenced by a variety of factors that has an impact on the processes of an organization. It has been studied in various professional contexts ranging from business organizations to educational environments. As indicated by McCaffrey (2010), the study of leadership from a scientific viewpoint based on the principles of research can be traced back to the beginning of the twentieth century. However, there is still ambiguity about the role of leadership in higher education (Portney, 2011). There is lack of researches on the role of leadership of university presidents of land-grant universities (LGUs).

Extensive investigation has been carried out on leadership, with specific focus on the role of leadership in organizations. Over time, many theories have been presented that have broadened the understanding of management towards the role of leadership in determining the competitive position of an organization in the market. The emergence of extensive literature related to leadership and its essence has made it a difficult task to define the concept of leadership. Northouse (2010) holds that research scholars and organizations have adopted different perspectives to develop an understanding about the concept of leadership. This understanding ranges from defining leadership as an inborn trait to the outcome of the process of interaction between a manager and subordinates.

Daft and Lane (2008) have asserted that leadership can be perceived as an interaction between the one who is leading and the group of followers, both of whom share a common objective. Additionally, the leader possesses the power to influence, persuade, or motivate these followers to pursue the chosen path, which is assumed to lead to desired changes. Leaders can take on different activities and practices to nurture an organization and help it move in a positive 
direction. A leader is responsible not only for the designing of a plan of action, but also for the successful implementation of the plan of action (Northouse, 2010).

Kouzes and Posner (2002) focused on the transformational role of leaders within the context of an organization and have identified five principles: "modeling the way, inspiring a shared vision, challenging the process, enabling others to act, and encouraging the heart" (Kouzes \& Posner, 2002; p. 13). Each of these principles is linked to the concept of the role of leadership as bringing about a positive change in an organization that leads to organizational growth and development. During an economic downturn, the model of leadership presented by university presidents seems to hold greater value for the success of institutions. A leader must facilitate the process of growth for an organization and its resources to make it strategically competitive in the market. From an academic perspective, the success of a university is not based on the revenue it is able to generate, but on the level of scholars it produces and the amount of extensive research work it carries out.

It should be kept in mind that leadership cannot be limited to business entities alone, as it is also considered to be an integral part of the academic arena. Colleges and universities, as with business organizations, need guidance from their management to regulate their different processes. The various processes managed by the Institute of Higher Education can be sorted into two broad categories: educational and extracurricular activities. Each of these processes requires a certain degree of expertise from management and university authorities.

The success and regulation of academic institutions, particularly higher educational institutions, are dependent upon the quality of leadership they have. A manifestation of this is evident in the form of university presidents who are responsible for managing the different activities in the university. These leaders need to develop a course of action that can help them 
achieve the objectives of their educational institutions while continuing to focus on growth and development (Kramer \& Swing, 2010).

The presence of leaders in the form of a university president is of strategic importance as well because many decisions they make can have a long-term impact on the functioning and development of the educational institution (McCaffery, 2010). Thus, a leader is bridging the gap between the internal and external environments of the university. Moreover, and the leader is responsible for providing the academic institution with the appropriate guidance needed for growth and development of the students, faculty, and reputation of the institution.

The strategic and facilitative roles of university presidents are associated with many responsibilities they must fulfill during the course of their tenure. Arx (2009) has offered a comprehensive view of the different sets of responsibilities allocated to the position of a university president. They range from simple tasks such as attending meetings to complex issues such as maintaining quality and decorum and facilitating development of the institution. Arx (2009) has further elaborated that these responsibilities are related to two different sets of customers that universities deal with: internal customers and external customers.

Internal customers for a university are students, faculty, and personnel responsible for overall administration. External customers, within the context of an educational institution, are the stakeholders outside the academic domain who are connected with the university, such as people or organizations that make donations, the government that formulates working policies, and the economic institutions themselves.

A university president has to effectively and efficiently deal with the different types of challenges occurring in the internal and external environments. These challenges can range from development of new academic policies at the level of government, education boards, to declines 
in the demand or interest in a particular field of study. While trying to meet these challenges, university presidents seem to rely on various leadership styles that they perceive as effective for their academic institutions (Brown, 2006).

A university president, as a leader, manages the different processes within the academic institution. The president also must manage all the processes and educational and extracurricular activities as effectively as possible. A university president must also keep a thorough check of the changes occurring in the external environment of the university and take the necessary measures to respond to those changes.

One of the major external challenges faced by the academic institutions in the United States is related to the financial constraints that arose from the financial crisis. This crisis has had a considerable impact on the functioning of the academic institutions. Stern (2008) has reported that the economic downturn has given rise to increased fees, reduced budgets, and associated pressure to manage the deteriorating financial condition in a more effective manner. It has also been suggested that because many academic institutions have been affected by a rapid decline in the economy during the recession, the ratio of funding and donations that they receive has become more critical to their survival.

The global economic downturn has given rise to financial limitations in the United States as well, with universities facing a decline in the ratio of funds that they had been receiving prior to the recession. For instance, the state of Arizona eliminated 5\% of the financial support it had been providing its universities, causing university management to increase tuition fees to cover the cost (Stern, 2008).

This dissertation focuses on exploring the attributes of leadership practices among the university presidents in land-grant universities located in all states in the United States. This 
chapter presents a background for the study along with a statement of the problem, the purpose of the study, the significance of the study, and an overview of the definition of terms.

\section{Background of the Study}

Various factors seem to have a significant influence on academic institutions. As indicated earlier, the internal decision-making process taken on by university president is one such source of influence. Along with that, certain external elements have a considerable impact on the rules and policies of the educational institutions operating in the market. One example of the external elements is the rules and policies developed by the government, which define the path of action for the institutions of higher education.

Higher education institutions (HEIs) in the United States are influenced by the laws and

policies developed and implemented by the government. The U.S. government has been focusing on developing effective educational policies that could promote quality education for its population. For the purpose of achieving the goals of making quality education accessible to the public and development of the fields of agriculture and mechanical arts, the U.S. government has developed certain policies. The Morrill Acts of 1862 and 1890 are examples that will be briefly covered in the following section.

The Morrill Act of 1862 was intended to be a source of support and development for educational institutions in all states in the United States. Brooks and Starks (2011) have stated that:

When Congress passed the first Morrill Act of 1862, it authorized the granting of 30,000 acres of federal land for every state with members to its congressional delegation based on 1860 census. The states were to sell this land and use the proceeds to establish 
colleges that would educate people in agriculture, home economics, mechanical arts, and other professions. (p. 75)

Thus, the land grant universities were specifically required to train and professionally groom scholars in the area of agriculture and mechanics. The Act was quite influential, as it was able to mark the beginning of the land-grant university (Lathbury et al., 2010). However, the black students still faced difficulty in accessing education in land grant institutions due to discriminatory attitude of the management.

Governmental and educational authorities were also concerned about the economic problems being faced by the land-grant universities. Such economic issues were making it difficult to achieve the mission of the land-grant universities. As a response, the Morrill Act of 1890 made the situation better, creating additional endowments, which provided a financial foundation for LGUs as well as allowing non-white students to enroll in land-grant institutions (Cross, 1999).

Since the approval and implementation of the Morrill Acts of 1862 and 1890, there has been a gradual increase in the number of land-grant universities in the United States. Johnson (2009) has reported that the number of land-grant universities has gradually increased as more universities turned their attention toward the areas of agriculture and mechanical arts. The passing of Morrill Act of 1890 has no doubt reduced the barriers to education for black students, however; the path of success for land-grant universities has not been smooth throughout their existence. The land grant universities had to deal with many challenges. The six reports of the Kellogg Commission on the Future of State and Lang-Grant Universities has reported that a few of these challenges included funding of educational programs, diversity in student and faculty, 
changing demographics and culture, industrial revolution and changing in the social classes (Sherwood, 2004).

Furthermore, the mission of land-grant universities has developed gradually. Initially the focus was on preparing students in agriculture and mechanical fields. With the passage of time, LGUs have also included the objective of serving as the primary vehicle for economic and social mobility as a part of their mission. LGUs can be regarded as the hub of learning, discovery, new technology, human development, lifelong learning, civic engagement, and spiritual fulfillment.

Leading in the $21^{\text {st }}$ century is challenging, therefore the presidents in land-grant universities are required to handle the various challenges as well as maintain stability in their educational institutions. McMurry (2010) stated that the complexity of environment with shifting values and economic conditions poses a unique challenge for academic leaders. The transformational leadership is usually sought in time of institutional crisis or when a new mission or mandate is sought to achieve the institutional mission (Paul, 2011).

The role of university presidents is a pivotal factor in the success and failure of the institutions. Eckel (2002) indicated that a strong leader could be a key factor in maintaining the function of the institution regardless of financial constraints. The type and quality of leadership is important with the increased responsibilities placed on university presidents. These administrative responsibilities are "finances and budgets; strategic planning; coordinating academic programs; personnel; soliciting donor support; government and board relations; alumni; athletic organizations; and institutional relations with the media, students and economic residents" (Weaver, 2005; p.11). Thus, the decisions made by university presidents to manage the institution directly influence the overall functioning. 


\section{The Problem Statement}

Clark Kerr (1984) has shown concern about the difficulty of getting a highly qualified leader to serve as a president of a higher education institution. The increasing responsibilities of university presidents and the challenges they have to deal with can limit their ability to serve as effective leaders. An additional problem is that little is known about how land-grant university presidents perceive their leadership skills or practices. This research will study leadership patterns of land grant university presidents in United States using the framework of five practices of leadership by Kouzes and Posner (2002). Furthermore, this study aims to explore the differences existing among presidents of LGUs in terms of leadership practices.

The higher education institutions operate through the mixed funding model, meaning that they are financed through several sources. The basic sources are government support, tuition and fees, endowments, gifts, and grants. According to the Morrill Acts of 1862 and 1890, land-grant universities are highly dependent on support from the government because the financial regulation of the institution is based on the funding and donations that it receives. Furthermore, other forms of financial support from stakeholders and influential members of their states are also a source of financial support. Recession can alter the ratio of the funding received by these universities.

The financial crisis that originated in the United States has disturbed the equilibrium of the HEIs. Marris (2010) has highlighted that of the many educational institutions that were receiving support from state governments in the form of funds and grants, approximately $85 \%$ of HEIs experienced difficulties due to the decrease in the ratio of support and funds. During the last three centuries, there was a "significant decrease in the percentage of a land-grant institution's budget that came from public coffers." (Sherwood, 2004; p. 4) In addition to that, 
according to the six reports of the Kellogg Commission on the Future of the States and LandGrant Universities, there were several factors that played a significant role in changing the role of land-grant universities in the $21^{\text {st }}$ century such as changing demographics of the American population and shifting between research and teaching (Sherwood, 2004).

This situation has propelled educational leaders to make changes in various activities of the institution and at the same time maintain the financial stability of the institutions. Most universities are trying to find ways to cut back their expenses in order to keep stable. Therefore, certain aspects of a university's operation have been hit hard by reduced income. Certain academic departments have been harshly affected as research and operating funds have decreased. Some of the institutions have responded to this issue by reducing their financial aid programs, putting building projects on hold, reducing library hours, decreasing their part-time and adjunct faculty, and cutting their budget overall. Justin Carter (2012) indicated there are several strategies used by educational leaders to manage the institutions during financial turbulence such as "cut programs and services, cancel professional development opportunities for faculty and staff, delay necessary facility renovations and construction, layoff employees, etc." (Carter, 2012, p.42) He further indicated that educational leaders were heavily dependent on other sources to generate revenues such as tuition and fees, donations and endowments (Carter, 2012).

However, these strategies seem to help academic institutions by providing them with temporary relief and by buffering them against the ill effects of recession for a short time. On a long-term basis, these strategies cannot be regarded as beneficial and effective. Brinkman and Morgan (1995) stated the reduction of government support to higher education institutions impacted the quality of education provided at these institutions. However, it has become 
necessary to make these strategic changes during the critical situation that was a result of the recession. The HEIs had no other option to pursue.

Even though universities have tried to balance out the situation by implementing these strategies, the institutions still suffered a blow due to lack of funds. Sherwood (2004) stated:

Some leaders of land-grant institutions were becoming increasingly concerned over what they saw as abatement or at least a shift in emphasis away from the principles upon which their institutions were founded. These leaders understood that some of the causes of this movement were their own making, but also recognized that American society, itself, was experiencing structural changes unparalleled in the history of the country." (p.5)

Therefore, the role of a university president becomes more important in higher education institutions. University presidents play a vital role in the facilitation and implementation of decisions based on the economic condition of the university. A university president needs to be aware of the challenges being faced by internal customers and external customers. For example, the financial support that deserving candidates (students) were receiving from the university also became difficult to manage. To continue providing scholarships to students, university presidents had to manage institutional budgets well according to the current financial status of their academic institutions. There was a possible course of action that could be adopted. University presidents could choose a non-compromising policy for scholarships, granting the financial support to only deserving students. But the current financial crisis makes things difficult, and it will be a difficult task to maintain this perspective.

Moreover, Gilley et al. (1986) stated:

A crucial component in the successful development and implementation of strategic mission is leadership. Recognition of the importance of quality leadership, and its 
necessity for institutional growth, was evident without exception at the school we visited. While many on the campuses gave kudos to faculty, deans, vice presidents, and others, the primary credit for institutional achievement was given to presidents as those who made a significant difference.(p.25)

Presidents need to make decisions that support the academic and non- academic endeavors of their university so that they can carry on with activities despite their financially challenging situation. The leaders in HEIs use these plans mostly to reduce the expenditure of colleges and universities, including reducing expenses, laying off personnel, or refraining from new hiring. Through leadership, several strategies were implemented in universities to maintain the success of the organization. Fisher (1991) has emphasized that effective presidents manage the final authority and make hard decisions. They also tend to support, motivate, challenge, and encourage the followers to the benefit of achieving the institutional mission. Moreover, effective presidents are risk-takers and have strong vision toward the future (Gilley et al., 1986). The same themes used by Kouzes and Posner (2002) in identifying the principles of leadership, which has been termed as "The Five Practices of Exemplary Leadership.” (p.3). Thus, a proper management of these challenges and issue can be considered a reflection of the effectiveness of leadership practices being used by a university president. The transformational leadership model offering by Kouzes and Posner (2002) of the university president is of great importance in maintaining the stability of the institution while dealing with the challenges during turbulent time.

\section{The Purpose of the Study}

The purpose of this study is to address the research problem through the study of the leadership practices of university presidents as described by Kouzes and Posner (2002) of land- 
grant universities in the United States. Furthermore, the study aims to find whether or not a difference exits among presidents of land-grant universities in terms of leadership practices and their perceptions of their own leadership.

\section{Research Questions}

The presidents of land-grant universities are the focus of the study, and the following research questions were investigated:

RQ1: What leadership practices are used by presidents of land-grant universities as reported in the LPI-self survey?

RQ2: Is there a significant difference in how land-grant university presidents perceived their leadership practices across the five principles of LPI? If so, which practices are perceived differently among land-grant university presidents?

RQ3: How do university presidents of land-grant universities think they use the leadership practices in their institutions as described by Kouzes and Posner (2002)?

\section{The Professional Significance of the Study}

The current topic is of importance for research scholars and their educational institutions, especially university presidents in land-grant universities. The professional significance of the study is as follows:

- The study will highlight how university presidents of land-grant universities perceive their leadership practices in managing the institution.

- The study is also of importance for university presidents, as it will identify their perception from a reflective viewpoint of their leadership styles. 
- Policy makers such as the different boards of governance can also benefit from the study, as it will provide them with an in-depth view of how university presidents perceive their leadership practices.

- The problem addressed in the dissertation will be of general interest for readers who want to update their knowledge about the leadership practices of university presidents of landgrant universities.

- The area of study is also signified, as it will contribute to the already existing body of literature pertaining to the role of leaders in land-grant universities.

- The study also can help improve the design of leadership programs at higher education institutions to prepare leadership in the future.

\section{Limitations of the Study}

The current study had certain limitations that impact on the degree of generalization of the results. The study was limited to:

- University presidents in land-grant universities only.

- State-funded universities.

- One perspective of leadership using self-report scores.

- Small sample of study due to the need of selective participants.

- Kouzes and Posner's (2002) idea of leadership.

\section{Organization of the Study}

This study is organized into five main chapters:

Chapter one: An introduction to the study, background of the study, the problem statement, the significance of the study, an overview of the methodology along with the research questions, and definitions of the key terms. 
Chapter two: A review of the major theoretical literature that is relevant to the study. An examination of the foundation of the leadership concepts is provided, elaborating on the literature relevant to leadership theories, with details that examine the leadership practices as described by Kouzes and Posner (2002). Also included is a review of the Morrill Acts (18621890) that shaped the land-grant universities in the United States.

Chapter three: A statement of the research methodology, including the design of the study, instrumentations, population and sample selection, data collection, and data analysis tools.

Chapter four: A presentation of the findings of the study and their relationship with the expectations and hypotheses reported in Chapter I.

Chapter five: A discussion, some conclusions of the study, policy implications, and recommendations for future research.

\section{Definition of Key Terms}

This section of the introductory chapter highlights the definitions of a few of the key terms used in the dissertation.

Leadership: Consists of these styles: "modeling the way, inspiring a shared vision, challenging the process, enabling others to act, and encouraging the heart" (Kouzes \& Posner, 2002; p. 13).

Leadership style: "Leadership styles are different approaches by which a leader may fulfill his or her leadership role." (Leadership Terms and Concepts, n.d)

Recession: "A significant decline in activity across the economy, lasting longer than a few months. It is visible in industrial production, employment, real income and wholesale-retail trade. The technical indicator of a recession is two consecutive quarters of negative economic growth as measured by a country's gross domestic product (GDP)" (Investopedia, n.d) 
Land-grant universities: "A U.S. College or university entitled to support from the federal government under the provisions of the Morrill Acts.” (Land-Grant University, n.d)

\section{Morrill act of 1862:}

An act of Congress (1862) granting each state 30,000 acres (12,000 hectares) of land for each member it had in Congress, 90 percent of the proceeds of which were to be used for the endowment and maintenance of colleges and universities teaching agricultural and mechanical arts and other subjects (Cross, 1999).

\section{Morrill act of 1890:}

The law authorized additional direct appropriations for the land-grant colleges of agriculture that had been established under the Morrill Act of 1862. The most significant feature of the second Morrill Act was that the 1862 schools could receive the additional funds only if they admitted blacks into their programs or if they provided separate but equal agricultural higher education to black students (Cross, 1999). 


\section{Chapter Two \\ Literature Review}

An extensive body of previous research is available on the context of leadership in academic institutions and has provided a foundation for the current dissertation. This chapter focuses on the theoretical and empirical perspectives pertaining to the issue of leadership in higher education institutions (HEIs). The chapter provides detailed insights into the theoretical foundations related to leadership concepts and theories. A detailed discussion on the leadership principles developed by Kouzes and Posner (2002) is also included in the literature review. The chapter contains information about the particular laws that shaped the form of policies in landgrant institutions and the role of leadership in higher education.

\section{The Conceptual Foundation of Leadership}

Leadership has described by various researchers, each reflecting on a different dimension of the characteristics of the position (Shapiro \& Stefkovich, 2011; Winston \& Patterson, 2006; Woods, 2004; and Zembylas \& Iasonos, 2010). The concept of leadership has evolved with the passage of time, with new theories and conceptual frameworks presented by various researchers. As stated by Northouse (2010), many researchers have tried to outline the dimensions of the process of leadership, the qualities of effective leadership, and the various factors that seem to benefit the process of leadership.

The wide array of research indicates that leadership cannot be regarded as a simple concept because it can be perceived from various points of view. Some scholars have regarded leadership as an innate capability of an individual, whereas other researchers have deemed it more appropriate to conceptualize leadership as a learned behavior that is influenced by the external environment. 
An interesting note is that during the twentieth century, as many as 65 leadership classifications have been offered by various researchers in an effort to identify the components of leadership (Northouse, 2010). The concept of leadership started emerging in 1531, and has been an area of discussion by many researchers. Rost (1993) has indicated that the concept of leadership has stirred up interest in various fields ranging from anthropology to business management.

Many theories for explaining the development of a leader or evolution of leadership have been put forward, including the great man theories, trait theories, behavioral theories, and role theory (Barman, 2009). Each of these theoretical frameworks seems to offer some explanation about the concept of leadership. However, a comprehensive framework of leadership is still lacking in the existing literature.

Junarso (2009) defined leadership as consisting of practices used by leaders "to transform values into actions, visions into realities, obstacles into innovations, separateness into solidarity, and risks into rewards. It's about leadership that creates the climate in which people turn challenging opportunities into remarkable successes."( Junarso, 2009; p. 99) These leadership practices provide a detailed explanation of the various principles that can be perceived as underlying characteristics adopted by a person as a leader. These principles are explained in the following section of the study.

\section{Five Principles of Leadership}

For this dissertation, the leadership definition by Kouzes and Posner (2002) was taken into consideration. They provided a classic definition of exemplary leadership by indicating that it involves the following factors (Kouzes \& Posner, 2002; p. 13):

- Modeling the way 
- Inspiring a shared vision

- Challenging the process

- Enabling others to act

- Encouraging the heart

Kouzes and Posner (2002) extracted these principles out of the philosophy that a leader who is successful and effective must be using these principles in action to gain positive outcomes. In other words, a leader can adopt these qualities to inspire, manage, and encourage followers in an effective manner.

Other researchers following the lead of Kouzes and Posner found related evidence that strengthens the idea of principles of leadership (Middlebrooks \& Allen, 2009). On the other hand, some researchers argue that the principles of leadership seem to portray general information. Moreover, some researchers applied the principles of leadership beyond entrepreneurial organizations, indicating that leadership, as a capability, can be useful for a variety of organizational setups. Agard (2011) suggested that the leadership framework offered by Kouzes and Posner (2002) is more in alliance with the objectives of organizations operating in the non-profit sector of a society. Thus, it can be concluded that the principles of leadership can work for the corporate world and can also benefit for leaders in not-for-profit organizations. Researchers also try to create a link between the principles of leadership presented by Kouzes and Posner (2002) and the different types of leadership styles. Parolini et al. (2009) agree with the principles of leadership by suggesting that there is a strong link between those five principles and the qualities attributed to servant leadership. Because a servant leader has a strong focus on helping other people in such a manner that they achieve their goals and targets, the five principles of leadership support this process of facilitation. Also, Taylor et al. (2007) use the 
leadership principles offered by Kouzes and Posner (2002) to explain the foundations of servant leadership. Servant leadership focuses on understanding the interests, needs, and benefits first as a way on serving others through collaboration and empowerment of the followers. The authors found that the principals in schools who were using servant leadership style were following the five principles of leadership. they were able to create feelings of motivation among the students and the faculty, as well as facilitate them to achieve their goals.

Moreover, Brown (2001) highlighted the usefulness of the leadership framework presented by Kouzes and Posner (2002), suggesting that the application of the five principles of leadership can help an organization in developing leaders who focus on the growth and development of individuals and organizations as a whole while taking a long-term perspective into consideration. It has been further asserted that the application of leadership principles can bring a positive change into academic institutions (Brown, 2001).

Strange (2005) stated that with an increase in the focus of leadership regarding group performance, the effectiveness of transformational leadership has also been highlighted. The principles of leadership outlined by Kouzes and Posner (2002) seem to be strongly linked with the qualities of a transformational leader. Therefore, the application of these principles in the workplace can give rise to improved performance of a team. The principles highlighted by Kouzes and Posner (2002) are discussed in detail below:

Practice one: Modeling the way. Modeling the way can be related to the simple act of doing the right thing so that followers can observe the actions of leaders and in turn follow in their footsteps. The whole idea of modeling the way is to provide a framework of values for the followers to see and model (Kouzes and Posner, 2002). Therefore, commitment from the followers can only be obtained if the leader is able to provide the followers with a framework of 
actions and values that is in accordance with each other. Furthermore, Bush et al. (2010) have explained that the role of a leader does not simply define a person who provides direction to others, but it encompasses other factors as well. The values that a leader holds are manifested through their actions.

Russell and Stone (2002) also agree with the idea that one of the most important features of a successful and effective leader is modeling the way. They indicate that the principles of leadership offered by Kouzes and Posner (2002) are a reflection of the characteristics of a servant leader. Thus, Russell and Stone (2002) incorporate the concept of modeling the way to elaborate on the behavior associated with servant leadership. There are two aspects of modeling the way:

1. Clarify values and beliefs. Modeling the way, as the name suggests, refers to a leader's capability of effectively reaching out to people by clarifying their values and beliefs (Kouzes and Posner, 2002). A leader does not need to give detailed speeches to get his or her point of view across to followers. An important thing to consider here is that a leader must ensure that there is no discrepancy between the values shared between the leader and the followers. Any difference between words uttered by a leader and their behavior is likely to result in loss of trust by the followers. People follow first the person, and then the plan. This is why modeling the behavior that best represents the plan and the shared goals are important. This eliminates any misunderstanding about the proposed actions and classifications that are essential in performing the task at hand. A follower who becomes lost in his or her actions can easily look to the leader and gain insight on what to do and how to do it (Kouzes \& Posner, 2002).

2. Set the Example. Leadership is portrayed through behavior. These leaders define a path for the followers by being a role model and displaying the same behavior that they expect 
from others. It is essential that they clarify the values in which they believe. By acting in the way they expect others to behave; they can then achieve the highest of standards and forge a path for the rest to follow (Kouzes \& Posner, 2002).

Middlebrooks and Allen (2009) also support the notion of modeling the way by indicating that a leader in HEI needs to manage the institution by portraying the behavior he wants the followers to adopt. Thus, a university president as a leader will behave in a manner that shows how he expects others (faculty and administration) to behave. Along with that, the students are also able to follow the lead. This provides the ultimate goal of modeling the way more stability and makes it easy for students to grasp the rules of the institution.

Practice two: Inspiring a shared vision. Another important principle that leaders use to influence followers is inspiring a shared vision. Kouzes and Posner (2002) define inspiring a shared vision as the ability of a leader to imagine the future and clearly articulate the vision to others, which enables the leader to gain the followers' support and belief in the vision.

Vernon and Byrd (1996; p.21) assert:

A clear vision of the organization's future provides both sound direction for the organization and a rallying point or goal for staff without such a common vision of the future or a shared sense of hope, people can become bogged down in a negative energy cycle and a feeling of hopelessness may set in.

Therefore, leaders in the $21^{\text {st }}$ century need to make key decisions and focus on the organization based on the shared values and needs of the staff and the customers. A leader can more clearly see how people behave towards one another and how cooperation should achieved among the personnel by using shared vision and values. An effective leader emphasizes how staff members 
need to make day-by-day decisions that are centered on the organization's values, rather than simply clear-cut rules, management sign-offs, or policies (Vernon \& Byrd, 1996).

It has also been pointed out that an effective leader has the ability to provide a vision to followers that provides them with a focal point for directing their energy. According to Dennis and Bocarnea (2005) a leader cannot facilitate shared vision in a group of followers if the crucial element of honesty is lacking. They further indicated that this task could be achieved only if a leader is able to create feelings of trust among the followers for his leadership and direction. With this trust, the followers can adhere to the plan better and learn much more from their leader. The tendency of a leader to focus on the development and maintenance of a vision alone is not enough to promote effectiveness. Kouzes and Posner (2002) also proposed the idea that an effective leader needs to present a vision that influences their followers positively. It has also been asserted that if a leader focuses entirely on vision, it is likely to result in failure of leadership instead of effective leadership (Bush et al., 2010). The two aspects associated with inspiring the vision are as follows:

1. Envision the future. This principle means that in order to motivate the followers, a leader should provide them with a vision and direction. The vision itself cannot stir feelings of inspiration in the people; it is the way that a leader presents the vision that motivates the followers. Leaders believe that they can truly make a difference, and in doing so, they must imagine what the organization can be in the future. They generally have a sense of the ideal outcome of their goals and practices as well as a structured definition of what to do. Inspiring a shared vision requires leaders to adequately portray their passion and sense of direction to their followers. They must be inspirational having the ability to identify the valuable opportunities that are in store when they arrive at their destination (Nicholson, 2007). 
2. Enlist others. A leader should persuade others to have a common vision such as their own. The leaders must know how to speak to the followers in a way that they will tune in and listen. The followers must believe that the leader has their interests and their needs at heart and can relate to their ideas. This way, the followers can relate to their leaders and know that the leader thinks their opinions are valuable. A leader should also be able to make a connection between the hopes and future perspectives of followers in such a manner that it becomes a shared source of inspiration for everyone. A leader should be able to imagine and portray the future possibilities in such a way that followers are attracted toward their perspective and feel inspired to be part of the leadership process (American Institute of Higher Education, 2011).

Practice three: Challenging the process. Challenging the process refers to the leader who emphases seeking out and accepting challenges, as well as leaders who challenge the process by recognizing and supporting innovative ideas, experimenting with new systems, and taking risks to bring about change (Kouzes and Posner, 2002). One of the most important outcomes of a challenge is the massive amount of learning that enables a leader to identify the best course of action and strategy to be followed. An effective leader would focus on development and progress and at the same time help people reach a level of excellence.

Brown (2001) also asserted that the most important element in the success of a leader is the ability to challenge traditional problem-solving patterns, and instill the use of innovation in problem solving. When a leader is able to challenge the common patterns of perception, followers go through the process of growth and development, thus polishing their problemsolving skills.

The tool of challenging the process can also be used while facing an economic crisis, lack of funds, and the threat of financial downfall. Nehls (2011) suggested that leaders in HEIs need 
to utilize their strategic vision and ability to cope with challenges in a creative manner to promote the process of fund raising. A strategic approach in the matter helps to better explain to the followers the plan and deal with the economic constraints by actively approaching the solution. Ramsden (1998) emphasized the role of a leader as a strategic planner. The building of a strategy and its application can be perceived as an integral part of challenging the process as the leader makes efforts to develop a plan of action that offers feasible solutions to the problems being faced by an organization.

Knuth and Banks (2006) confirm that Kouzes and Posner (2002) have taken the right approach by incorporating the principle of "challenging the process" into the leadership framework. It has also been discussed that this attribute helps a leader in creating a positive change for scholars in academic institutions, as the leader is able to allow followers to utilize their creativity and to learn to deal with the external challenges in an effective manner. There are two aspects in challenging the process:

1. Seeking opportunities. Challenging the process refers to a leader's ability to take benefit from challenges in the external environment and to use the challenges as a growth opportunity instead of treating them as a possible threat. Every challenge brings the possibility to learn something new, to alter the previous course of action, to adapt to make things more favorable, or to experiment with different ideas that may prove useful. Leaders are expected to think of challenges as a possible alteration of their plan; however, it could result in some newfound goals and novel opportunities. An effective leader continuously searches for opportunities to improve and to grow through these challenges. These leaders are always looking for innovative ways to challenge the status quo to enhance the organizational performance. 
2. Experimentation and taking risk. An important aspect of challenging the process is risk-taking. Leaders know that positive change involves experimentation and risk-taking. Leaders often have to seek and deal with challenges to make progress in their goals and the vision as a whole. Thus, leaders are naturally risk-taking people who are willing to do things that may not have a clear-cut outcome. This is important because without taking a risk, it is impossible to know what else may lie ahead of the task such as opportunities and possible growth chances that comes in part by exerting effort through managing challenges. In doing so, they experiment and take risks. But leaders understand that experimentation and taking risks as learning processes can lead to success or failure (Kouzes and Posner, 2002).

Practice four: Enabling others to act. Apart from offering inspiration to people, a person who is able to guide a group toward a positive course of action is also a source of effective leadership. A leader has the capability to enable followers to transfer their ideas into practical implications. Enabling others to act includes teamwork, trust, confidence, and empowerment (Kouzes and Posner, 2002).

A leader's ability to facilitate the growth process among personnel and students is also reflected in HEIs as pointed out by Savin-Baden (2000). Krill et al. (1997) have evaluated the proposition of enabling others to act as a case study of the leadership principle. They have further asserted that this principle is a combination of two different factors that are related to each other. One of the factors highlighted in the study was that of collaboration, while the other factor focused on the role of a leader as a source of strength for the group. The perspective adopted for enabling others to act has been summarized as "the segment of leadership concerned with a leader's ability to enlist the support of others to inspire work on their own accord for the betterment of the organization" (Krill et al., 1997; p. 43). Enabling others to act has two aspects: 
1. Foster collaboration and trust. One of the prime goals of a leader is to develop feelings of mutual trust and cooperation that can motivation people to achieve their desired tasks (Kouzes \& Posner, 2002). Gaining trust of followers involves creating an environment in which the followers feel comfortable asking questions at any given time. It is also essential to give enough face-to-face time to each individual. This provides an opportunity to raise any questions that the person may have as well as create more personal interaction between the leader and follower. Making the follower feel ownership of projects creates a better collaboration and ensures that the follower is aware of his or her responsibility. A sound relationship that involves trust helps everyone support the main vision easily.

2. Strengthen others. A leader also offers the support that is required by followers to achieve their goals and objectives. One of the main areas of consideration related to this principle is the ability of the leader to provide people with a sense of empowerment that enables them to participate in activities that lead to the attainment of common goals (Kouzes \& Posner, 2002).

For leaders to enable others to act, they must deliver on the promises they make. A leader makes sure that each person is involved and understands all the changes that occur. Each follower has to have a sense of ownership for his or her contributions to the vision. At the same time, the followers need to remember that they are part of a team. It is the leader's responsibility to maintain positive relationships among team members. . This can be done by inspiring and enabling people to act for the attainment of common goals and engage in teamwork. Leaders work to make people feel committed and to inspire the followers to follow the vision (Kouzes \& Posner, 2002).

Practice five: Encouraging the heart. The last principle focuses on the ability of a leader to be a source of encouragement and support for the followers and to celebrate victories 
(Kouzes and Posner, 2002). The leader offers encouragement to followers by focusing on their achievements and offering words of encouragement and appreciation (Kouzes and Posner, 2002). This practice enables the leaders to be a source of confidence for their followers (Langone, 2006). The appreciation and encouragement also become a source of positive reinforcement for their followers, which motivate them to repeat positive actions in the future.

Pounder (2001) evaluated the capability of a leader within the context of a university to offer motivation and encouragement to followers. This capability has been linked with the transformational and transactional leadership pattern. Motivating followers is not only about providing them with a sense of direction, but also involves the use of rewards and incentives that can be a source of attraction for them. The two aspects involving encouraging the heart are as follows:

1. Recognizes the contributions of others. The role of a leader becomes important as the leader can utilize the enthusiasm of followers as the motivating force to facilitate their efforts in a certain direction. Often, the path that leads to the top is exhausting and can be weary on the followers. Leaders know that encouragement can motivate followers to achieve the shared vision. It is important to keep the followers motivated because as a team, both the leader and the followers are a source of inspiration and strength for each other.

2. Celebrates the values and victories of the groups. An important way to encourage the heart of the followers is to recognize their contributions. This can be done by simple acts or more intricate gestures. Some organizations and institutions like to hold banquets or some sort of public recognition program with awards and other forms of appreciation. The leader's job is to show appreciation and gratitude for the contributions that people make to celebrate the values. Celebrations can build a strong sense of identity in a community and help the community 
members become more committed, thus increasing the productivity in the long run. This sense of community can also carry an organization through difficult times (Kouzes \& Posner, 2002).

\section{Important Laws that Shaped the Land-Grant University}

Education in the United States has been through various transitions and alterations. HEIs have been exposed to external pressures from the environment in the form of laws and policies developed by the federal and state governments. The development of land grant universities can be attributed to the changing perspective of government officials towards the need of institutions where education is based on the fusion of scientific and industrial elements (Sherwood, 2004). Prior to the introduction of the Morrill Acts, a large number of educational institutions offered degrees in professional fields such as law and politics. There was a lack of universities which offered programs related to agriculture and mechanical arts (Cross, 1999). A subsequent result of this changing perception has been an increased emphasis on providing an opportunity to acquire knowledge in the domain of agriculture and mechanical arts. Moreover, university education in the field of agriculture and mechanical arts was considered more relevant to the needs of the middle class students in the U.S.

In the 1850 s, the U.S. government felt the need to encourage HEIs to diversify the areas of study that they were offering to meet the changing requirements of the society. There was a strong need to have graduates with the right set of skills enter the fields of agriculture or mechanical arts, but the HEIs at that time were not focusing on these areas of specialization (Rauner \& Maclean, 2008). The two major sources of influence on HEIs have been the Morrill Acts of 1862 and 1890, which have changed the direction for universities and laid the foundation for land-grant universities (LGUs). 
Morrill Act of 1862. The efforts of Justin Smith Morrill are reflected in the Act of 1862 , which supported the donation of land owned by the federal government to HEIs. Morrill was greatly inspired by the development in Europe within the field of agricultural education. He considered agricultural education to be a source of benefit for the working class students within the U.S. The Act received opposition in the beginning. But once it was approved and implemented it had a significant level of influence on the role of HEIs in training students in the fields of agricultural and mechanical arts (McClure, Chrisman, \& Mock, 1985). President Buchanan was a major source of resistance, as he rejected the approval of the bill in 1857 . This resistance was embedded in the belief that introduction of educational policies is solely the jurisdiction of the States. The suggestion of focusing on agricultural and mechanical arts courses in universities was provided by Morrill, who was not a government official. Buchanan considered his suggestion as a form of external influence, which challenged the power of decision-making by the States about educational matters.

An additional factor, which developed such antagonism from government officials, was that the bill was regarded as favoring the northern areas of the U.S., compromising the stability of the southern region (Cross, 1999). At that time, the majority of people in Congress belonged to Southern states. Therefore, they held a negative opinion about the bill. After the Civil war (1864), Morrill sent the bill for review again. Iowa and Kansas became the first two states to give approval for land grant propositions presented by Morrill. Other states followed this lead after the civil war ended in 1865 (Cross, 1999).

The land-grant universities (LGUs), as the name suggests, are dependent upon the donation and funding they receive from the federal government. They were established with the help of the federal government's donation of 30,000 acres of land, the profit of whose sale was 
used in the construction and maintenance of universities. Kansas State Agricultural College was formed as an outcome of the Morrill Act. Other notable examples in this regard are Texas A \& M University, South Dakota State University, Oklahoma State University, etc. It is also important to point out that not all of the states have established separate land grant universities. Some of the states, such as Nebraska, started offering courses of agriculture and mechanical arts alongside liberal arts in already established universities (Cross, 1999).

With the passage of time, the LGUs have expanded their scope of courses from specific emphasis on agriculture, mechanical and military tactics into other disciplines such as pharmacology and domestic economy. In addition to this, the agricultural domain was also expanded through the inclusion of courses pertaining to the fields of genetics, hybridization, veterinary medicine, etc. (Wishart, 2004).

Another important development can be seen in the form of the Hatch Act, passed in 1887. This Act emphasized the use of experiment stations for the purpose of learning and application of practical knowledge in the field of agriculture. Therefore, land grant universities were able to effectively position themselves as the source of scientific investigation pertaining to agriculture.

The Morrill Act of 1862 created a significant basis for establishing HEIs in the United States. However, it also had some flaws which limited the positive influence of the Act. One of the major problems was that the funding was inadequate to run the academic programs and maintain the faculty. Another issue that was highlighted after the implementation of the Morrill Act of 1862 was that of discrimination against non-white students, as some black students were denied access to colleges on the basis of their cultural and ethnic background.

Morrill Act of 1890. In 1890, a second Morrill Act was established to expand admission to land-grant institutions to include all students. Race was not an admissions criterion (Morrill 
Act, 1890). Thus, upon considering the flaws in the previous act of 1862, Congress offered an amended version of the Act with the following propositions (McClure, Chrisman \& Mock, 1985):

- Further financial support to HEIs

- Initial grant of $\$ 15,000$, with $\$ 1,000$ increase on an annual basis for ten years

- Grant of $\$ 25,000$ after completion of ten years

- Support by the federal government for particular courses

- Allowance for non-white students to enroll in LGUs.

These amendments were beneficial to university students, as the HEIs had access to a greater degree of support from the government, and students with diverse cultural backgrounds found an opportunity to study in universities as the barrier of discrimination weakened (Geiger, 2005). The federal government was able to increase its control in the admission policies of the LGUs, thus making it favorable for African-American students. It was also decided that separate educational entities for black students would be established to ensure that these students could access quality education. This resulted in the development of institutions such as Langston University in Oklahoma. The proponents of LGUs also considered the educational opportunities to be an important part of women's education. Courses in the field of home economics provided benefits to female students. The inclusion of cooperative extension was also a major characteristic of this Act.

Native Americans also benefited from LGUs, as the approval of the Equity in Educational Land Grant Status Act in 1994 prompted the academic institutions in states such as the Dakotas, Nebraska, Kansas, etc. to provide admission to Native Americans. Moreover, the $20^{\text {th }}$ century has given rise to further developments in LGUs. The curriculum of LGUs has been 
expanded through integration of the fields of arts, humanities and social sciences in the land grant institutions. The existence of LGUs provides students with an opportunity to gain access to educational institutions with an affordable fee structure. Furthermore, LGUs also support admission of students from diverse ethnic and cultural backgrounds. The amalgamation of theoretical and practical skills also makes LGUs a valuable means of higher education for middle class students (Wishart, 2004).

Changes occurring in the U.S. agricultural sector have affected the outlook of LGUs. For instance, the declining interest of individuals in conventional farming and rise in business-owned farming has increased the need for individuals having in-depth knowledge about agriculture. In 1990s, the LGUs have increased their focus on research and empirical investigation to meet the rising demand of a workforce equipped with scientific knowledge in the agricultural sector.

One of the factors that has been challenging for LGUs is the rising number of immigrants who have diversified the cultural landscape of the U.S. Many land-grant universities found it difficult to respond to the needs of these different cultural groups (Sherwood, 2004). Kellogg Commission on the Future of State and Land-Grant Universities was established to respond to such issues. The commission intended to identify the factors that challenge LGUs. It was also responsible for identification of solutions to handle these issues. The commission has put forward 6 reports in this regard. It was concluded that LGUs needed to modify their mission, broadening it to address the changing dynamics of the student population and educational sector.

Sherwood (2004) has asserted that in order to maintain the valuable position of LGUs, university management and government officials need to devise a unified body which can bring changes in the mission, policies and curriculum of LGUs to ensure that these institutions are able to meet the challenges of today's world. Instead of focusing on the vision only, LGUs need to 
devise concrete steps to follow. This will allow them to handle the changes occurring in the $21^{\text {st }}$ century as the composition of the U.S. population and its educational needs have altered with the passage of time.

\section{An Overview of the Role of Presidents in HEIs}

A common perception of the role of presidents in higher education institutions (HEIs) is based on the notion that a university president is supposed to maintain discipline and to monitor the implementation of various rules and regulations. On the other hand, a more comprehensive view of the responsibilities of a university president indicates that the role of a president within an educational institution goes beyond the domain of simple administrative and supervisory activities.

The role of a university president has been explored and analyzed using different perspectives, focusing on their leadership skills, ability to manage teams, implement policies, handle financial matters, and regulate the academic and extra-curricular activities of their respective institutions. Researchers have also emphasized the social role of the university president as central to the development of youth who will support progress of society (Bok, 1982; Bowen, 1997). These roles such as planning, leadership, and external relations are focused heavily in all three areas, and sometimes there is significant overlap among them. Moreover, the future of the organization is achieve through university presidents by leading the strategic planning, and implementation of the growth and development of university programs. In this way, leaders and followers accept the challenges and meet the requirement to improve the organizational performance. University presidents plan renovation of facilities, and consider opportunities to expand or adapt programs and services offered to students (Bok, 1982; Bowen, 1997). 
The leadership responsibilities of the university president coincide with the responsibilities of other faculty members of the institution. The deans and heads of departments look to the president for ideas and collaborations. They are the functional chief executive officers of most universities; however, some universities have a chancellor as the chief executive.

However, the actual executive is the president of the school. Some schools give the ceremonial title of chancellor to a retired university president. The president is responsible for the day-to-day administration of the institution and responsible for implementing the directions and leading the way for the faculty of the university (Education Encyclopedia, 2013). Bok (1982) has also stated that following WWII, universities evolved into educational entities that trained students in linking with the larger aspect of their social life, society. The traditional role of the university president has also been altered as a result of the change in student's and society's needs. It has propelled the academic leaders to bring the required changes in their set of responsibilities.

Academic development and preparing students for the future by offering appropriate guidance is not the only role of a university president. It has also been asserted that the position demands a high focus on research and scholarly development of its students. It is much more than mere implementation of policies and facilitation of development of curriculum (Dunn et al., 1985). The role of a university president has evolved and expanded with the passage of time.

Even though the administrative responsibilities of university presidents have been emphasized in literature (Altbach et al., 2011; Bess \& Dee, 2008), researchers have also highlighted other responsibilities associated with the position. As stated by Kramer and Swing (2010), the role of a university president spans activities ranging from management of the faculty and staff at the campus to providing direction to the academic institution. Thus, the role of a university president in HEIs encompasses a wide array of activities. Lorange (2002, p. 259) 
proposed a comprehensive view of the role of university president by indicating that it is related to activities such as the following:

- Clarifying and determining direction

- Positioning the institution

- Improving the climate through communication

- Decision making and adjudication

- Representing the institution

Each of these activities performed by the president is focused on maintaining the effectiveness and competence of the processes of HEIs and ensuring continued success, despite the various challenges emerging in the external environment. The position of a university president in a higher education institution is of strategic importance as the university president tries to identify the threats and opportunities present in the environment and make decisions that have an impact on the progress and development of the institution.

Englehardt et al. (2009) pointed out that the university president, as head of the academic institution, bears the responsibility of administrating academic affairs in such a manner that they follow the policies outlined by the state. In addition to this, the university president has the responsibility of creating an alignment between policies and laws approved by the state and of ensuring their effective implementation. Thus, the rules and regulations being generated outside the academic arena also seem to have an influence on the course of action and direction adopted by the president.

Another dimension added to the role of a university president is evident from the ethical responsibilities associated with the position. As Walker (1981) asserted, the presence of a leader in a university is needed to ensure that the scholarly and administrative components of the 
institution are managed effectively while adhering to ethical standards. Along with that, the role requires that the president be a source of ethical inspiration for everyone ranging from administrative staff members to students.

The position can be perceived as very demanding as the occupant of the post is not only supposed to look after the administrative and academic aspects of the institution, but also required to manage the capital, human, and other resources as effectively as possible. The president also needs to be able to handle internal and external challenges, and take benefit from the opportunities present in the environment. The most critical aspect of the position is that the president must create a link between the external environment and the internal operations of the university (Padilla, 2005). Some challenges of being a university president are related to maintenance of educational standards, international outreach, financial issues, governance and accountability, as well as institutional autonomy. Especially in the $21^{\text {st }}$ century, funding has become increasingly limited, and alternative sources of funding have not been fully developed. Fundraising in higher education has become a critical component for financing the institution. Fundraising has been identified as a fundamental component of the overall mission of the university. With decreased funding from the government, fundraising has become a necessity in institutions. Thus, an effective leadership style of a university president can affect fundraising and affect the university success as well (Nicholson, 2007).

The financial role of a university president has also been emphasized by researchers. Bess and Dee (2008) elaborated on budgetary planning indicating that the final authority of approval of a budget plan, as presentable to the board of directors, is in the hands of the university president. Planning for the budget is usually started off by the chairs of the respective departments who will in turn send it to the dean for approval. The dean has the responsibility of 
evaluating the budget plan prior to submitting it to the vice president, who deems the plan appropriate and sends it to the president for final approval.

The financial management of university resources is one of the most prominent responsibilities of the university president (Bess \& Dee, 2008). The president must properly allocate resources, understand the economic challenges and threats of the external environment, and have the ability to follow a course of action that will lead the academic institution on a continued path of success. Considering the economic crisis, the financial decisions that a university president must make determine the level of stability that educational institutions will be able to maintain during a time of turbulence. Presidents need to make a variety of tough decisions to deal with matters such as "increase tuition fees and reduce aid, to freeze recruitment or layoff staff, and a slowdown in some college building programs" (Fullan \& Scott, 2009, p. 4). These decisions require the administrative skills of the president. The financial crunch has required them to be more narrowly focused and to adopt an approach that emphasizes the financial management of the institution.

\section{Previous Research on the Role of University Presidents}

In recent years, many dissertations on academic leadership examined the university leadership of presidents (Brown, 2010; Drumm, 2011; Mathern, Dennis, 1998; McMurray, 2010; Mills, $2004 \&$ Ihedigbo, 2012). None of these researchers explained the leadership of university presidents at land-grant institutions, where the leadership role is a critical factor in today's economic time.

For example, Mills (2004) examined the leadership of a university president during a crisis situation. Specifically, the study examined the presidential leadership in three case studies: an airplane crash in 1970, people killed at the athletic department at Oklahoma State University 
in 2001, and people killed at Texas A\&M University in 1999. These crises required presidential leadership. The author aimed to explain how certain leadership action leads to different results. Furthermore, the study allows leaders in higher education institutions to review their actions during a crisis and learn how to take actions to better prepare for the future. The leadership frames used in this study are political, human resources, bureaucratic, and symbolic. The result indicates that effective presidential leadership occurred mostly on the human resource frame following by symbolic, political, and bureaucratic frames. A president's sense of loss plays a critical role in shaping the human resource frame in the leadership role. However, the bureaucratic frame can be significant during the crisis phase of saving life or property. Overall, the leadership styles vary by crisis, and presidents need to properly adapt the right style at the right time.

A study done by Mathern (1998) discussed the leadership strategies of American university presidents. The research has used leadership strategy model to study how the leaders managed change. This model consists of three types of leadership models. These are: the linear, adaptive, and interpretive models developed by Chaffee in 1985. Chaffee randomly sampled university presidents who served at four-year accredited institutions. The linear model suggests that the leaders make direct action involved in the strategic plans and decision-making process to achieve the goals. The adaptive models are suitable for leaders who want to challenge the process by taking risks and using innovation. The interpretative model defines a leader as a facilitator who guides individuals to meet certain objectives. The study concluded that the university presidents adapted all three models of leadership in different ways. In general, experienced university presidents prefer the linear model, but the interpretative strategy model or the adaptive strategy model is required when the presidents were dealing with bringing change. 
Moreover, recent studies about the leadership and the role of university presidents suggest shifts in the role of university presidents from the traditional, bureaucratic leadership styles towards the democratic models of transforming leadership, servant leadership, and relational leadership (McMurray, 2010). Many researchers tried to understand what makes leadership effective. Despite this mounting literature on leadership, a gap remains in the specific exploration of relational leadership in the role of the university president. This study helps understanding of the role of university president in the relational leadership model. Therefore, the study implies that the relational leadership model is the central theme among the presidents in the leadership role in their university.

Another study by Brown (2010) investigated transformational, transactional, and laissezfaire leadership styles of historical black college and university (HBCUs) presidents. It also examined presidents' perceptions of the styles, values, and attributes needed to lead effectively, and it provided advice to those aspiring to the presidency. There were 72 presidents at HBCUs, public and private, in the U.S. during 2005 to 2010. A mixed method was used for data collection, compromising: designed survey, focus groups, interviews, data from university web sites, and vitas provided by participants. The results of the study clearly indicated that HBCU presidents utilized transformational or transactional leadership behaviors in their roles. The data revealed that cultural values, attributes, and leadership styles make a difference in their success or failure. The data also revealed that mentors and mentoring played a key role in the development of these HBCU presidents.

Another study of university presidents at historically black colleges and universities (HBCUs) by Ihedigbo (2012) examined the leadership practices and their preparation factors on determining the effectiveness of academic leadership. The study focused on to developing an 
understanding about the reasons that some presidents of HBCU member institutions are more effective than others. The author discussed several strategic steps needed to ensure strengthening of the qualities of future leaders of higher education institutions. Quantitative approaches were used to examine the relationships between higher education institution leaders' success and preparation factors. The study aimed to find some preparation factors that were common among successful leaders of institutions of higher education, especially historically black colleges and universities. The study concluded that outstanding and ordinary presidents have equal knowledge of leadership.

Drumm (2011) focused on the relationships between the presidential leadership and fundraising goals. Since university presidents faced many challenges in keeping daily operation of their institution during the economic downturn, fund raising is an important part of their leadership activities. Bolman and Deal (1990) developed four types of leadership: structural, symbolic, political, and human resource leadership models. The leadership styles of university presidents are altering how much giving could be brought to the university. Thus, university presidents as fundraisers play an important role in shaping the leadership frame for this study. There were 70 presidents in public and private not for profit high research universities. The result indicates that the human resource leadership frame received a high finance gain during the six-year period compared to other leadership frames. Therefore, the use of human resource by leaders can help in receiving higher amount of donation.

\section{Previous Studies Using the Leadership Practices Inventory}

There have been numerous studies in the area of leadership practice inventory, and some of those are discussed in this paper (Aaker, 2003; Anderson, 2004; Bauer, 1994; Castro, 2003; 
Du Plessis, 2008; Hempowicz, 2010; Orman, 2002; Oliver, 2001; Plowman, 1991; Rozboom, 2008).

For example, Plowman (1991) assessed the leadership practices and found the differences between the college's environment and leadership practices of college presidents. There were 28 presidents within the State University System of Florida (SUSF) and 82 Vice Presidents who were responsible for academic affairs, business and finance, student affairs, and institutional advancement. The presidents completed the LPI-self Surveys, while their vice presidents completed LPI-observed surveys. The finding suggests there are significant differences in leadership practices between presidents and vice presidents. Presidents were rated higher, in the $70^{\text {th }}$ percentile as compared to the score provided by the followers. Moreover, vice presidents consistently rated the presidents' leadership practices and the institutional environments lower than did the presidents.

Another study done using LPI in December 1993 was called "Are the Leadership Practices of College Presidents in the Northeast Distinct from those of Leaders of Business and Industry?" by Margaret Bauer. The author focused on determining whether there are significant differences in terms of leadership practices between academic presidents and business presidents in challenging economic times. Business leaders mainly focused on the profit outcomes, while academic leaders focused on freedom, tenure, promotion, and organizational structures. The LPIself and observed surveys were distributed to the two samples. The key findings were that the leadership practice enabling others to act earned the highest means scores in both groups. However, enabling others to act was considered higher in academic leader by compared to the business leaders. Effective leadership practices for academic leaders ranked as follows: inspiring a shared vision, challenging the process, modeling the way, and encouraging the heart. While the 
business leaders ranked the leadership practices as follows: challenging the process, modeling the way, encouraging the heart, and inspiring a shared vision. The author suggested two metapractices for envisioning (CTP, ISV, and MTW), and implementation (EOA and ETH).

Another study conducted by Oliver (2001) on Chief Student Affairs Officers in Texas, analyzing their leadership practices. The study aimed to examine the current leadership practices of chief student affairs officers in order to understand their leadership practices and their influence in empowering excellence of the institutions. Moreover, many chief student affairs officers provide some leadership roles as support to the presidents in decision-making processes beyond their area. However, previous research shows leadership skills lacking in chief student affairs officers. The sample included LPI-self surveys for the chief student affairs officers and LPI-observer surveys for their followers at five research universities in the United States. The result found that the mean scores were high on the LPI-self instrument compared to LPI-observer scores. However, the ranked order for the five leadership practices was the same in both groups as follows: enabling others, modeling, encouraging, challenging, and inspiring.

Another study in which LPI helped to disprove misconceptions was a study done at the University of Colorado in Denver. It was called "Footprints to the Academic Deanship: Women, Generative Leadership, and Power" by Orman in 2002. The study developed a model of leadership styles and communication skills of female academic deans at public-funded institutions using a mixed method. The findings concluded that the leadership practices ranked were in the same order as ranked by deans and observers: enabling others to act, modeling the way, challenging the process, encouraging the heart, and finally, inspiring a shared vision. However, deans ranked themselves higher on all five practices compared to their observers. 
Aaker (2003) carried out a study on a sample of Executive Female Administrators. The purpose of this study was to see if there is a difference between female executive administrators in student affairs and female administrators in academic affairs at Tennessee community colleges in terms of leadership practices. A quantitative method was used in LPI self and observer surveys. The result indicated that there were no differences between the groups, and both groups had the same ranked order with enabling others to act as the first practice engaged in by the participants followed by modeling, encouraging, challenging and inspiring.

Another study was done by Castro (2003), aiming to study the leadership practices of academic deans. This study focused on examining the relationship between emotional competence and leadership effectiveness among academic deans in higher education. The sample included 36 participants from Chief academic officers (CAO), Deans and academic department chairs. Data were collected using the Emotional Competence Inventory and the Leadership Practices Inventory (self only). The result found that the mean scores for the deans were higher compared to the mean scores of chairs and COA on all five leadership practices, except for modeling. In sum, the result indicated that the successful academic unit using different leadership skills to manage their performance.

A study by Rozeboom (2008) focused on discussing the various practices of the chief student affairs officers with regard to their leadership skills. The discussion of these leadership practices is a great source of information for all the chief student affairs officers across the nation and can help them polish their abilities. It should also aid them in taking their institutions to higher levels of excellence and discipline along with causing them to be more influential leaders in their organizations. When the results are examined in the terms of the mean scores of enabling others to act, it is found that most of leaders emphasize maintaining high quality relationship 
with the people around them. This was followed by the leadership practices of modeling the way, encouraging the heart, challenging the process and sharing the vision.

The five practices of leadership are ranked in the same exact order by both the chief student affairs officers and their direct reports. But in the case of self-reports, the scores are quite a bit higher than those found in the study of the LPI by Kouzes and Posner (2002). The scores are even higher than the ones present in the database of Kouzes and Posner (2002). The factors of ethnicity and gender made no difference in the results as a whole. The only differences found were on the basis of various educational institutions and their educational backgrounds. The conclusion of the study suggests that the chief student affairs officers should examine the major findings of this study to get a better understanding of the differences between the self-view and the opinions and comments of the observers. The student affairs officers should give special attention to the feedback that they get from others. Along with this, they should invest more in the leadership sector and make the results of this study available to the managers responsible for carrying out this whole process in a transparent manner (Rozeboom, 2008).

du Plessis (2008) investigated the leadership practices of women superintendents of public school divisions. The researcher used a variety of data collection methods, including interviews, member checks, field notes, and a reflective journal, as well as an LPI-self survey. There were only 8 interviews in the study. The study concluded that women superintendents focused on building relationship with others. They also used their leadership positions to handle the issues of gender discrimination.

A recent study done by Hempowicz (2010) focused on studying the transformational leadership Characteristics of College and University Presidents. Kouzes and Posner's (2007) well-established Leadership Practices Inventory (Self Instrument, 3rd Edition) 
was used to measure leadership practices. There were 219 presidents of private four-year institutions invited to complete the LPI self-survey developed by Kouzes and Posner (2007). About 146 (66.67\%) presidents participated in the study. The results of the research revealed that enabling others to act was the most frequently used leadership practice, followed by modeling the way, inspiring a shared vision, encouraging the heart, and challenging the process.

\section{Summary}

This chapter provides information about various laws that shaped the form of policies in land-grant universities. Furthermore, the role of leadership in higher education is discussed in the context of the research that has been carried out. This chapter includes an analysis of the previous research done and the latest information regarding it. This chapter has included and explained a number of different theories and concepts about leadership.

Many theories for explaining the development of a leader or evolution of leadership have been put forward such as the great man theory, trait theories, behavioral theories, and role theory. Each of the theoretical frameworks seems to offer some explanation of the concept of leadership. However, the comprehensive framework of leadership is still lacking in existing literature (Vandenberg, \& Sandmann, 1995). For this dissertation, the leadership definition by Kouzes and Posner was taken into consideration. They have provided a classic definition of exemplary leadership by indicating that it involves the following factors: modeling the way, inspiring a shared vision, challenging the process, enabling others to act, and encouraging the heart.

This chapter also discussed the role of a leader in offering encouragement to followers by focusing on their achievements and offering words of encouragement and appreciation. This practice enables leaders to be a source of confidence for their followers. This appreciation and encouragement also become a source of positive reinforcement for the followers, which motivate 
them to repeat the positive set of actions in the future. This chapter also included various efforts made by the government of the United States to provide students with the right skills in the universities so that they could be a part of the national economy as skilled workers equipped with all the right tools. To make this arrangement successful and practical, various acts and laws were passed so that the government could play an effective role in the higher education of its youth. In this context, the Morrill Acts of 1862 and 1890 are the most important ones.

This chapter has also highlighted the role of a university president as the leader who is responsible for making decisions, clarifying, and determining the direction of activities to improve the institutional climate through communication, and representing the institution in a dignified manner. In addition to this, the university president has the responsibility of creating an alignment between the policies and laws approved by the state, and ensuring their effective implementation. Thus, the rules and regulations being generated outside the academic arena also seem to have an influence on the course of action and direction adopted by the president. 


\section{Chapter Three}

\section{Methodology}

This section of the methodology chapter briefly highlights the various approaches adopted by the researcher to collect data from the research participants. Researchers can use a variety of methods while exploring an area of interest. Each of the methods used has its own strengths and weaknesses. The approach used by the researcher has been termed a mixed research approach to understand the leadership practices of university presidents of land-grant universities in the U.S. In a mixed method, the researcher explains the findings by using quantitative and qualitative methods to expand our knowledge of the phenomenon under study (Parse, 2009). Barnham (2012) states that "the two methodologies often work in effective symbiosis with each other and each brings to the other a level of understanding that it would not otherwise achieve" (Barnham, 2012; p. 4) .

In this study, the researcher uses the Leadership Practices Inventory (LPI)-self survey (quantitative method) developed by Kouzes and Posner (2003) along with the interview description (qualitative method) to gather data. The research process uses a blend of quantitative and qualitative approaches known as a mixed method to expand the understanding of the leadership practices of university presidents at land-grant universities in the United States.

\section{Design of the Study}

This research examined the leadership practices adopted by university presidents of landgrant universities as described by Kouzes and Posner (2002). Furthermore, this study aimed to find whether a difference exists between participants in terms of each practice. To define the best practices of university presidents, the research used a "mixed" method approach. 
First, the researcher sent out a link to a leadership profile inventory (LPI) self-survey by email to all presidents of land-grant universities. However, due to the limited responses, hard copy LPI-self surveys were mailed to the presidents who did not return the LPI self-survey on time. The aim of the survey was to understand the leadership practices being used by the university presidents of land-grant universities in the United States.

Second, interview participants were selected according to the LPI score of highest and lowest among the returned surveys. However, when the LPI scores were similar among the participants, random selection was made to select the interviewees. After determining the interviewees, the researcher sent an invitation via email to these presidents asking them for an interview, reminding them that their participation was important to the research, but it was still voluntary. Moreover, the researcher explained to them the terms of confidentiality and anonymity. The aim of the interview was to get an inside perspective from each president as to how he or she performed in the organization according to the five practices set by Kouzes and Posner (2002).

The next step focused on the presidents who agreed to proceed with the interview. An email was sent asking them for the best time and date for the interview with a reminder about the participant's confidentiality and anonymity. Moreover, the researcher informed the participants that results of the study would be available through West Virginia Libraries.

Upon completion of these steps in determining the participants, the interviews took place. On the day of interview, the researcher informed the participant that a recording device would be used to easily access the data and would be used by the researcher only to transcribe the answers. The researcher reminded the participants that this interview was voluntary and that if there were any questions they did not want to answer, they had the option to do so. Fortunately, this was not 
the case, and all of the five participants completed all five questions as outlined in the interview protocol.

Moreover, the interview questions are semi-structured that allow the researcher to use a standard list of questions with the participants, as well as ask other related questions to probe further. This allows the participants to describe the phenomena in a more narrative way (Whiting, 2008). The interview questions were structured to bring forth the thoughts, feelings, and perceptions of the participants about their exemplary leadership practices. The interview protocol consisted of the five questions related to the leadership practices of exemplary leadership as explained by Kouzes and Posner (2002). The questions were designed to give a better understanding of the leadership practices of university presidents at land-grant universities. Before each question, the researcher gave the interviewee a brief explanation of the meaning of the practice.

\section{The Interview Questions}

\section{Question one: Modeling the way.}

What do you think about the practice of modeling leadership? Is it important or not? Can you tell me how you model leadership in your position as a president in your university?

\section{Question two: Inspiring a shared vision.}

What do you think about the importance of sharing a vision as a president of a LGU?

How do you communicate a shared vision with others?

\section{Question three: Challenging the process.}

What does it mean to challenge the process at a land-grant university? How do you show others that the status quo must be challenged? 


\section{Question four: Enabling others to act.}

What do you think about the importance of enabling others to act independently to fulfill a common mission? How do you enable others to act independently to fulfill a common mission?

\section{Question five: Encouraging the heart.}

What do you think about the importance of encouraging the heart in your institution? How do you encourage the heart in your university?

\section{Participants of the Study}

To identify the population, the website of higher education resources has listed all landgrant institutions in the United States (Higher Education Resources Hub, 2008). From the university web site, information about the president and biography indicate the year he or she was appointed as president of the university.

Considering the scenario, the population of the study comprised all the presidents in the land-grant universities (see Appendix A). Ideally speaking, the best course of action would be to gather information from all the presidents to have access to as much information as possible about the leadership principles of the land-grant universities. The LPI-self survey was emailed to all 65 -university presidents of land-grant universities. The response rate of $40 \%$ is considered acceptable since few participants are available to complete the survey on time (Methodist Communication, 2009). There were 26 LPI self-survey (40\%) returned from the total population.

To obtain data from the participants by using a qualitative interview, the researcher used purposive sampling. Purposive sampling allowed the researcher to produce information that enhances the findings of the study (Teddlie \& Fan Yu, 2007). There were only six interviewees whom the researcher selected based on the participants who returned the LPI-self surveys. The 
sampling technique used for the purpose of identifying the potential participants in the study was purposive sampling. A list of structured questions was presented to the interviewees to obtain responses about the use of leadership on the basis of the five leadership dimensions. All participants were serving currently as presidents of land-grant universities for at least two years.

\section{Instrumentation}

In this study, the Leadership Profile Inventory (LPI) instrument developed by Kouzes and Posner (2003) was used to measure the leadership practices of participants. This tool essentially helped assess the extent to which these practices are being used to increase the level of efficiency and effectiveness. LPI helps to discover the potential of any individual to become a leader, as being a leader requires use of correct tools and acceptable feedback.

Mixed research methods were used in the form of qualitative and quantitative research methods emerging from the LPI instrument. Five leadership practices were generated as a result of personal experiences of leaders through case studies in-depth interviews. Those five best leadership practices include: (1) Modeling the Way, (2) Inspiring a Shared Vision, (3) Challenging the Process, (4) Enabling Others to Act, and (5) Encouraging the Heart. The LPI (individual-form) instrument consists of 30 items (each practice has six items) assessing all five principles of exemplary leadership described by Kouzes and Posner (2002). These items provide a way for individual leaders to measure the frequency of their own specific leadership behaviors on a 10-point frequency scale. A higher value stands for more frequent use of that particular leadership practice as follows: (10) Almost Always, (9) Very Frequently, (8) Usually,

(7) Fairly Often, (6) Sometimes, (5) Occasionally, (4) Once in a While, (3) Seldom, (2) Rarely, (1) Almost Never (see Appendix B).

Six statements related to each leadership practice are listed below: 


\section{Practice one: Modeling the way.}

Statement1: I set a personal example of what I expect of others.

Statement 6: I spend time and energy making certain that the people I work with adheres to the principles and standards we have agreed on.

Statement 11: I follow through on the promises and commitments that I make.

Statement16: I ask for feedback on how my actions affect other people's performance.

Statement 21: I build consensus around the common set of values of running our organization.

Statement 26: I am clear about my philosophy of leadership.

\section{Practice two: Inspiring a shared vision.}

Statement 2: I talk about future trends that will influence how our work will get done.

Statement 7: I describe a compelling image of what our future could be.

Statement 12: I appeal to others to share an exciting dream of the future.

Statement 17: I show others how their long-term interests can be realized by enlisting in a common vision.

Statement 22: I paint the "big picture" of what we aspire to accomplish.

Statement 27: I speak with genuine conviction about the higher meaning and purpose of our work.

\section{Practice three: Challenging the process.}

Statement 3: I seek out challenging opportunities that test my own skills and abilities. Statement 8: I challenge people to try out new and innovative ways to do their work. 
Statement 13: I search outside the formal boundaries of my organization for innovative ways to improve what we do.

Statement 18: I ask, "What can we learn?" when things don't go as expected.

Statement 23: I make certain that we set achievable goals.

Statement 28: I experiment and take risks, even when there is a chance of failure.

\section{Practice four: Enabling others to act.}

Statement 4: I develop cooperative relationships among the people I work with.

Statement 9: I actively listen to diverse points of view.

Statement 14: I treat others with dignity and respect.

Statement 19: I support the decisions that people make on their own.

Statement 24: I give people a great deal of freedom and choice in deciding how to do their work.

Statement 29: I ensure that people grow in their jobs by learning new skills and developing themselves.

\section{Practice five: Encouraging the heart.}

Statement 5: I praise people for a job well done.

Statement 10: I make it a point to let people know about my confidence in their abilities.

Statement 15: I make sure that people are creatively rewarded for their contributions to the success of our projects.

Statement 20: I publicly recognize people who exemplify commitment-shared values.

Statement 25: I find ways to celebrate accomplishments.

Statement 30: I give the members of the team lots of appreciation and support for their contribution. 
Table 3.1

LPI Self-Survey Version: Means and Standard Deviations

\begin{tabular}{lllllc}
\hline & Model & Inspire & Challenge & Enable & Encourage \\
\hline Mean & 47.0 & 40.60 & 43.90 & 48.70 & 43.8 \\
SD & 6.0 & 8.8 & 6.8 & 5.4 & 8.0
\end{tabular}

Note. Adapted from The Leadership Practices Inventory: Theory and Evidence Behind the Five Practices of Exemplary Leaders by James Kouzes and Barry Posner. Available on the Internet at http://media.wiley.com/assets/463/74/lc jb_appendix.pdf 
Means and standard deviations for each practice of the LPI-self leader of Kouzes and Posner (2002) study are presented in Table 3.1. Furthermore, means and standard deviations scores of LPI determined that the enabling others to act practice is the most repeated one among leaders. Then comes modeling the way, while challenging the process and encouraging the heart are similar in usage among leaders. Inspiring a shared vision practice is considered to be the least common practice used by the leaders (Kouzes \& Posner, 2002).

Kouzes and Posner's (2012) percentile ranking was used as a continuum to rank each of the five leadership practices from high, moderate, and low scores for each participant. These rankings are based upon a study of more than 12,000 leaders who utilized the LPI-self survey and who scored at or below the following given levels for each practice: high percentile range from 70 to 100 , moderate percentile range from 30 to 69 , and low percentile range from 1 to 29 (See Table 3.2).

The LPI instrument is reliable. Basically in terms of internal consistency reliability, an instrument is said to be more reliable if it contains fewer inconsistently rated items and a reliability score above 0.60 . The internal consistency reliability coefficient (Cranbach's alpha) of self-report of LPI is 0.75 or above in each of the five dimensions of leadership practice, which means that all of the five measures of leadership practices possess strong internal reliability coefficients, making LPI a reliable instrument (See Table 3.3). These five practices also have strong test-retest reliability with coefficients at 0.90 and above.

A study by Zagorsek et al. (2006) showed that LPI as an assessment tool is more reliable and accurate when dealing with people who possess low to medium leadership competencies rather than the high-quality leaders. This leads to the result that LPI is best when used for the purpose of learning, training, and developing rather than simply choosing a leader. 
Table 3.2

The Leadership Practices Inventory: Percentile Ranking

\begin{tabular}{lllll}
\hline Percentile & Model & Enspire & \\
Ranking & & & \\
\end{tabular}

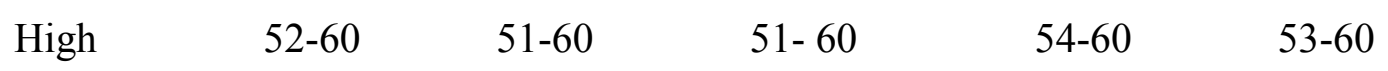

$70-100$

$\begin{array}{lrrrr}\text { Moderate } & 43-51 & 39-50 & 41-50 & 47-53\end{array}$

30-69

Low $\quad 20-42 \quad 13-38 \quad 17-40 \quad 21-46 \quad 15-41$

1-29

Note. Adapted from The Leadership Practices Inventory: Percentile Ranking by James Kouzes and Barry Posner (2012). Available on the leadership challenge website at http://www.leadershipchallenge.com/UserFiles/PercentileRankingFINAL012012.pdf 
Table 3.3

Internal Reliability (Cronbach's alpha) for Self-Version

\begin{tabular}{llllll}
\hline & Model & Inspire & Challenge & Enable & Encourage \\
\hline Reliability & 0.77 & 0.87 & 0.80 & 0.75 & 0.87
\end{tabular}

Note. Adapted from The Leadership Practices Inventory: Theory and Evidence Behind the Five

Practices of Exemplary Leaders by James Kouzes and Barry Posner. Available on the internet at http://media.wiley.com/assets/463/74/lc_jb_appendix.pdf 
The internal reliabilities of the leadership practices are highly consistent over time.

Leadership Practices Inventory possesses high predictive and face validity. People believe and easily understand the findings of this tool, and it also helps in predicting leaders ranging from low to moderate and high leadership competencies. Face validity (content validity) is high as it truly measures what it purports to assess, and the results are useful and meaningful for the respondents. The results have a strong correlation with the various measures of performance, which helps in predicting the effectiveness of leaders, and so it can be said that the predictive validity of the LPI is high. Carless (2001) conducted a study to assess the construct validity of this tool with a sample of 1400 subordinates from a finance company. It was found that LPI is highly valid in assessing the higher order transformational leadership.

\section{Researcher as an Instrument in Interviews}

The researcher acts as a very strong and powerful instrument in the interview part of the qualitative research. In a qualitative study, the researcher is considered "the primary instrument for making sense of the phenomenon under study" (Barrett, 2007; Abstract). There are a number of ways in which by acting as an instrument, the researcher can provide a huge amount of information that otherwise is not available. The researcher in an interview can be a source of the information the interviewee is providing, by getting into the depths of the words and interpreting. The researcher can also play her role very effectively if she successfully records all the information through electronic digital recordings of the interviewee's answers.

The researcher can be a better instrument by not being candid, but instead asking relevant questions in a manner that could bring out the truth behind certain events or facts that people usually know from a different perspective. As an instrument, the researcher should be more focused upon the feedback required than on unnecessary details that do not have anything to do 
with the objective of the research. As far as keeping the bias out of the research project, the researchers can avoid it in interviews by avoiding the questions that lead the interviewee in a certain direction. To avoid bias in research, the researcher should never attempt to put his or her desired answers in the interviewee's mouth. In fact, the interviewer should be asking neutral questions that could help in getting better quality information. Barrett (2007) indicates that the researcher's approach and experience of the phenomena could influence the findings. However, the data presented from the interviewees seem to reflect what the participants were actually doing, and the conclusion is based on their thoughts and words. The interview part aims to interpret an experience from the participant's "point of view." The qualitative researchers attempt to understand how people interpret their world by using an empathic understanding of their own thoughts, feelings, and motives to understand the actions of others (Maykut \& Morehouse, 1994).

Chapter four presents a clear description on how the data collection was carried out to remove the researcher and participant bias.

\section{Data Collection}

All of the data obtained for this study were collected personally by the researcher using LPI individual-report survey, and by conducting interviews of selected participants. The researcher generated a mailing list of all university presidents of land-grant universities in the United States. Each university president's contact information was taken from the university website, specifically from the Office of the President link, which includes the participant's institution mailing address, the president's biography, email address, and phone number. After receiving approval from West Virginia University's Institutional Review Board for the Protection of Human Subjects and a permission letter from the instrument developers, the 
researcher sent an email to the participants requesting them to participate in the Leadership Profile Inventory, self-report survey during the first week of November 2012. They were informed that their participation was important to the study and were encouraged to return questionnaire answers within a two-week period. Also, the email included a specific ID and password for each president and the link to answer the survey questions. The email outlined the purpose of the study and its objectives and also assured participants of data anonymity (See Appendix C).

However, participants who failed to respond within the two weeks were sent a second email as a reminder and were encouraged to participate in the survey. A sample of the invitation to participate in the survey are included is Appendix D. Because the data collection occurred during the end of the fall semester, when most presidents are busy with their academic work, the researcher deemed it suitable to send reminders to participate in the study. Thus, a third followup was emailed sent out to the participants, within a two-week period, aiming to increase the participation rate (See Appendix E). Responses to the survey were collected using an electronic version of LPI from the publisher website, with permission from the instrument developers. However, only 10 surveys were returned electronically from the participants. The researcher noticed that most emails were sent to the presidents' assistants first, and most declined or ignored requests were made by the assistants according to the priority schedules for the presidents. Also, some presidents were in a transition period and were no longer available to participate in the study. Then, the researcher tried to follow up with a phone call to the presidents' assistants, asking them to help with delivering the LPI-self survey to the presidents in person. A hard copy of the LPI self-survey was requested and mailed to the president's office address directly by the 
middle of January 2013, with a return stamped envelope to the researcher's home address. By the end of February 2013, the researcher received 16 LPI surveys at her home address.

Upon completion of the survey, the researcher selected interviewees based on the list of participants who have returned the LPI-self surveys. An email invitation was sent to each president. Presidents who agreed to do the interview replied back with the day, time, and the method to conduct the interview, either by phone or by fact-to-face interview. Following that, an email confirming the day and time was sent to the participant's email address. Six presidents were scheduled for the interviews. As the study proceeded, on the day of the interview, one potential participant was no longer available due to an urgent medical reason. Thus, five participants successfully completed the answers during the interview protocol.

The interview started with the researcher expressing gratitude to the participants for providing time for an interview. Then the researcher shared a brief description of the purpose of the study, the benefit of the study, and the importance of accuracy of information in the research. The participants were verbally reassured of the maintenance of their anonymity and confidentiality. The interview progressed when the participants provided the researcher with informed consent about answering the questions and using the digital recording device. The questions were put forward one by one for the presidents to answer, with the choice to decline any query they did not wish to answer. Finally, the interview process was concluded by assuring the confidentiality and anonymity of respondents, and thanking the participants for their time and effort to help complete the study.

\section{Data Analysis}

The responses obtained by the online or paper surveys (data file) were tabulated with the Statistical Package for the Social Sciences (SPSS). After tabulation of the data, the researcher 
checked the normality and homogeneity of the responses. The assumption of homogeneity of variance was tested by Mauchly's test of sphericity. If the result did not meet the assumption of normality, a log of the data was taken. But if the assumption of homogeneity of variance was not fulfilled, the feature of data transformation was used.

Descriptive statistics was used to report means, standard deviations, and frequencies, which can be used to describe the leadership practices of the university presidents. Multiple displays such as tables were used to present findings of the survey data, whereas inferential statistics was used to analyze the differences and relationships between the variables. There are three research questions, and the statistical methods associated with each research question are described. Furthermore, the null hypothesis and the proposed statistical analyses to answer each research question are listed below:

Research question one. What leadership practices are used by presidents of land-grant universities as reported in the LPI-self survey? To address this research question, a descriptive analysis used a statistical review of the individual's survey, which was completed using a Statistical Package for the Social Sciences (SPSS) to assess the score for each university president. They responded on a self-rating of the LPI 30 items, yielding (1) a score from one to ten on each item, (2) a total from 6 to 60 on each dimension, and (3) a combined average mean score for each dimension. For example, the total score for dimension one was determined by adding the individual's ratings for the six items associated with the dimension.

The survey ratings and resulting scores of the president's self-rating are referred to as “self” ratings. A combined score was calculated for each participant on all five practices (1) Modeling the Way, (2) Inspire a Shared Vision, (3) Challenge the Process, (4) Enable Others to 
Act, and (5) Encourage the Heart. Means and standard deviations for each of the five practices of leadership scores were reported as rank-ordered according to the survey results.

The percentile ranking for each individual's scores was calculated according to the LPIself percentile ranking provided by Kouzes and Posner (2012). The normative scale allowed the researcher to rank each of the five leadership practices along a continuum of high, moderate, and low scores for the cumulative scores of each participant. These rankings were based upon a study of more than 12,000 leaders who utilized the LPI-SELF and who scored at or below the following given levels of 70 to 100 as high, 30 to 69 as moderate, and 0 to 29 as low. These percentile rankings are further discussed in Chapter 4.

Research questions two. Is there a significant difference in how land-grant university presidents perceived their leadership practices across the five principles of LPI? If so, which practices are perceived differently among land-grant university presidents? H02: There are no significant differences between leadership practices of university presidents of land-grant universities in the United States in terms of the five perceived practices of leadership scores. To test this research question, a "repeated-measures" (within subject) analysis of variance (ANOVA) was used to compute the variables. For this analysis of variance, it was the five dimensions for all participants report the repeated values. There is no between-subjects factor for this analysis.

If the analysis of variance yielded a statistically significant finding $(p<.05)$, then the effect size was computed using partial Eta squared. After that, a "multiple comparison" was computed to determine which pairs of the dimensions differ significantly $(p<.05)$. Thus, comparisons were tested. For example, modeling the way vs. inspiring a shared vision and so on were compared to fully determine which dimensions show a statistical difference. The rating 
may show statistically significant higher ratings by the presidents for modeling the way than for inspiring a shared vision. The number of comparisons to be computed should not be sufficient to pose a threat of Type 1 error (Bretz, Hothron \& Westfall, 2011).

Research questions three. How do university presidents of land-grant universities think they use leadership practices in their institutions as described by Kouzes and Posner (2002)? The data analysis process took place after each interview and throughout data collection (Maykut \& Morehouse, 1994). The researcher used a qualitative data analysis method known as a "Constant Comparative" method developed by Maykut and Morehouse (1994). The constant comparative method combines inductive category coding that takes a concurrent comparison of all the units of meaning obtained (Maykut \& Morehouse, 1994). Steps in preparing the data for analysis began with transcribing the recording interview by the researcher. Then, the researcher labeled each transcribed recording with a fictitious name in order to maintain confidentiality and maintain a tracking system of the information. Then, the researcher inserted all the participant's answers under the question asked. For example, the researcher inserted all the answers related to question number 1 with the identify label for each participant together.

After that, the researcher coded each existing theme for each participant with the same color for each theme under each practice. If the same theme was found in another question, the researcher coded the theme with the same color as chosen before. Valenzuela and Shrivastava (2008) described a method of analysis of interview data by identifying the code for each theme as they emerge. In this way, each code represented the common patterns and regularities in the participant's answers. This enabled the researcher to locate comments within the context of the overall interview at a later date. Lincolon and Goba (1985, p. 334-346) explained this strategy as identifying the data units of information that will sooner or later serve as the basis for defining 
the categories.

Next, the data were arranged according to the existing common themes identified by the researcher that provided a foundation for evaluating the data with reference to the principles of leadership provided by Kouzes and Posner (2002). The interview questions were analyzed to identify the presence or absence of the theme according to LPI categories as follows: (1) Model the Way, (2) Inspire a Shared Vision, (3) Challenge the Process, (4) Enable Others to Act, and (5) Encourage the Heart. The codes and themes were analyzed to find units of meaning that were examined to find emerging themes (Maykut \& Morehouse, 1994). The researcher identified the important theme or concept that could give the meaning for each practice. For example, when the participant talked about the collaboration and trust between leader and followers, this concept related to the leadership practice "Enabling Others to Act." Then, data were coded into categories according to each leadership practice.

The units of meaning were reviewed carefully to discover recurring themes and ideas; pieces of information that seemed to overlap with others were combined (Maykut \& Morehouse, 1994). The researcher then explored the data codes that could be placed in another category and used the "looks like" or "feels like" criteria to identify the data codes that were similar or different from the categories or themes (Maykut \& Morehouse, 1994, pg125). The researcher carefully reviewed all the data cards and categories to look in overlap or ambiguity that could exist through the analysis process of "coding and categorizing."

Finally, themes were compared between the categories of the five practices. The responses of the participants gave were compared and contrasted, with the codes and themes developed from the interviews, and compared to the result of LPI-self surveys. In general, the interview analyses compared with the results from LPI-self surveys represented a compilation of 
best leadership practices of these university presidents at land-grant universities.

\section{Anonymity and Confidentiality}

It was imperative for the researcher to maintain the anonymity and confidentiality of the participants. The data collection process required the researcher to note the name of the university with which a participant was affiliated, and the name of the university president, as well. However, this information was not communicated to the readers in any form. The discussion about the responses from the interviews followed the ethical guideline of anonymity, as the researcher focused only on the content of the responses, without indicating the person or the university. The researcher verbally reassured the participants of their confidentiality verbally, and further assured them that the data obtained in the research through questionnaires and interview were used only for research purposes, without naming the people involved in the study. The responses of individual presidents were not highlighted with their names or their universities; anonymity and confidentiality were maintained. For this reason, each interviewee had a separate record number; the data were kept secure, with access available only to the researcher. 


\section{Chapter Four}

\section{Results}

This chapter focuses on analysis of the quantitative and qualitative data generated from the administration of LPI self-surveys and interviews of the presidents in land-grant universities. The evaluation of the data is based on the three research questions of the study. The resultant findings provide answers to these questions, indicating the trend of leadership practices being of presidents in land-grant universities. This chapter is divided into three sections. The first section focuses on analysis of results of LPI self- surveys. The second section looks at the analysis of the differences between the use and perception of the five practices of LPI. The third section entails the analysis of qualitative data, focusing on evaluation of how university presidents think they use leadership practices in their respective land-grant universities. The three research questions are related to this study, and the proposed statistical analyses to answer each research question are listed below:

\section{Question one: The researcher asked, “ What leadership practices are used by presidents of land-grant universities as reported in the LPI-self surveys?”}

A statistical review of the individual's LPI self-survey score was completed using a Statistical Package of SPSS to assess the score for each university president on each statement. They responded with self-rating of the LPI 30 items, yielding (1) a score from one to ten on each statement, (2) a total from 6 to 60 on each practice, and (3) a combined average mean score for each practice.

The survey ratings and resulting scores of the president's self-rating are referred to as “LPI-Self” ratings. A combined score was calculated for each participant on all five practices: (1) Modeling the Way, (2) Inspiring a Shared Vision, (3) Challenging the Process, (4) Enabling 
Others to Act, and (5) Encouraging the Heart. Means and standard deviations for each of the five practices of leadership scores of the sampled university presidents of land-grant universities in the United States were reported as rank-ordered according to the survey results.

Table 4.1 shows that a majority of the presidents focused on the behavior of enabling others to act, which was a predominant leadership practice among university presidents (mean= 53.92). It was followed by modeling the way, which held the second rank a (mean= 52.19). Inspiring shared vision was in third order with a mean of 51.27, which suggests that presidents have a moderate focus on this aspect. As far as challenge the process is concerned, it was ranked in fourth position with a mean value of 50.77. Last, the lowest score was obtained for the practice of encouraging the heart (mean=49.27), with the highest standard deviation scores were also observed in this category $(\mathrm{SD}=5.780)$. On the other hand, enabling others had the lowest degree of variation in terms of the response provided by the participants $(\mathrm{SD}=3.006)$. This indicates that there was more agreement related to the leadership practice of "Enabling Others to Act" and less agreement among the participants related to "Encouraging the Heart," thus resulting in the highest level of standard deviation $(\mathrm{SD}=5.780)$. Also, the standard deviation of encourage the heart is higher than the standard deviation of "enabling others to act." It means that the respondents had a greater degree of variation in the responses to encourage the heart.

The score on each leadership practice represents the degree of usage of the leadership components associated with that practice. For instance, enabling others to act consists of active listening, supporting decisions of others, and treating people with respect, a focus on interpersonal relationships and providing individuals with alternative courses of actions to select from to attain the objectives. 
Table 4.1.

Rank-Ordered Means and Standard Deviation for the Leadership Practices Inventory-Self (LPI-

Self) of Sampled University Presidents at Land-Grant Universities in the United States (N=26)

Leadership Practices $\quad$ Mean Standard Deviation

\section{Combined Scores}

\begin{tabular}{lcc}
\hline Enable Others to Act & 53.92 & 3.006 \\
Model the Way & 52.19 & 4.631 \\
Inspire a Shared Vision & 51.27 & 4.738 \\
Challenge the Process & 50.77 & 4.885 \\
Encourage the Heart & 49.27 & 5.780
\end{tabular}

*Maximum $=60$ 
A high score represents a greater tendency of leaders to display these behaviors, while low scores indicate little utilization of these leadership behaviors.

The second leadership practice, "Modeling the Way," includes clarity about leadership philosophy, seeking feedback from others about the impact of the leader's actions, compliance to standards, establishment of unanimously understood organizational values, use of personal example, and keeping promises. A high score shows that the leader significantly engages in these behaviors, while a low score represents less participation in these behaviors.

A third practice is "Inspiring a Shared Vision," which involves the following: providing a vision for attaining interests and objectives, emphasizing meaning of work, appealing to others for sharing and following the vision, portraying the future in an appealing way, and discussing implications of future changes in the organization. A high score in this category means that the leader is focusing on these practices to a significant extent, while a low score suggests a low emphasis on these behaviors. "Challenging the Process" involves use of innovative ideas, seeking external opportunities, focus on learning, experimentation and risk taking, and establishing goals and focusing on these practices to a significant extent, while a low score suggests a low emphasis on these behaviors objectives. A high score for challenging the process means that the university presidents are frequently engaging in the aforementioned behaviors. On the other hand, low scores show that the presidents do not engage in these behaviors on a regular basis.

The last leadership practice included in LPI was "Encouraging the Heart.” It entails offering appreciation and support to people, acknowledging the commitment of others, using creative rewards, showing confidence in people, praising, and celebrating achievements. Presidents scoring high in this category show that they regularly use appreciation, rewards, and 
acknowledgement to support people in continuing or enhancing performance. On the contrary, low scores show that the presidents do not offer verbal or non-verbal appreciation to others, do not reward positive behavior, and do not acknowledge the contributions of other people.

Furthermore, the data analysis has included analysis of the separate categories of five leadership behaviors in terms of each statement and the related mean and standard deviation as depicted in the following sections:

Practice one: Enabling others to act. The researcher presented the leadership practice of university presidents' mean scores along with the corresponding standard deviation. Each statement related to enabling others to act was ranked from highest to lowest mean (see Table 4.2). Developing cordial relationships with others by treating them with respect and dignity was a principal behavior (Mean=9.65). This grouping related to statement number 14 (I treat others with dignity and respect) had the highest rank as well as the highest mean score of all other practices out of the thirty statements. This suggests that university presidents at land-grant universities ensure that their interactions with other people are based on respect, thus retaining the dignity of others. Another statement with a high mean was statement number 19 (I support the decisions that people make on their own), which means that the presidents encourage people to make individual decisions and also offer support to make and implement the decisions autonomously. Statement number 4 (I develop cooperative relationships among the people I work with) indicates that the president focuses on formation of effective interpersonal relationships, based on mutual cooperation.

The lowest mean value for this practice was for statement number 29 (I ensure that people grow in their jobs by learning new skills and developing themselves). 
Table 4.2.

University Presidents’ Mean Leadership Practices Inventory Ratings for Statements Related to Enabling Others to Act

\begin{tabular}{lcc}
\hline LPI Statement Number & Mean & SD \\
\hline Statement fourteen & & \\
- I treat others with dignity and respect. & 9.65 & 0.562
\end{tabular}

Statement nineteen

- I support the decisions that people make on

0.736

their own.

Statement four

- I develop cooperative relationships among

0.908

the people I work with.

Statement nine

- I actively listen to diverse points of view.

8.96

1.076

Statement twenty-four

- I give people a great deal of freedom and

8.50

choice in deciding how to do their work.

Statement twenty-nine

- I ensure that people grow in their jobs by

8.27

1.251

learning new skills and developing themselves.

Maximum*10 
This statement reflected the behavior of facilitating career development of other individuals with a mean score of 8.27 . Also, enabling others to act showed the least variability among other practices. It indicates that most university presidents at land-grant universities agreed on the importance of this leadership practice compared to any other practice on the LPI survey. In Table 4.3, the frequencies and the percentages related to the percentile ranking of the leadership practice enabling others to act were presented. The frequency count indicates that the score of respondents ranged from 50 to 60 . Kouzes and Posner (2012) stated that individual scores from 54 to 60 are considered high, and scores from 47 to 53 are considered moderate. Most participants (14 out of 26) ranged from 54 to 60, while the remaining 12 participants scored in the moderate level from 50 to 53 . This means that the university presidents perceived that they engaged in this practice at the high and moderate levels.

Practice two: Modeling the way. The six statements related to the leadership practice "Modeling the Way" were grouped together with the means and the standard deviation scores reported in Table 4.4. The highest mean score of "Modeling the Way" was the statement number 26 on LPI-self survey (I am clear about my philosophy of leadership). This represents the university president's ability to develop a comprehensive and understandable framework for leadership philosophy, and the mean is high (Mean=9.62). Statement number 11 (I follow through on the promises and commitments that I make) confirms the notion that the leaders fulfill their promises and commitments despite facing difficulties. Statement number 21 (I build consensus around the common set of values of running our organization) means that the university presidents are focusing on unanimously agreed-upon standards and values to regulate the processes of the organization. 
Table 4.3.

Frequency Counts and Percentages of Specific Scores on Kouzes and Posner's Leadership

Practice Enabling Others to Act from the LPI-Self Survey Completed by University Presidents.

\begin{tabular}{lcc}
\hline Individual Scores & Frequency & Percentile Ranking Level \\
\hline $54-60$ & 14 & High $(53.84 \%)$ \\
$47-53$ & 12 & Moderate $(46.15 \%)$ \\
Total & 26 & \\
\hline
\end{tabular}


Table 4.4.

University Presidents’ Mean Leadership Practices Inventory Ratings for Statements Related to Modeling the Way

\section{LPI Statement Number}

Statement twenty-six

- I am clear about my philosophy of leadership.

Statement eleven

- I follow through on the promises and commitments that I make.

Statement twenty-one

- I build consensus around the common set of values of running our organization.

Statement one

- I set a personal example of what I expect of others.

Statement six

- I spend time and energy making certain that the

7.77

1.505

people I work with adhere to the principles and

standards we have agreed on.

Statement sixteen

- I ask for feedback on how my actions affect other people's performance.

SD

.469

.736

1.021 
These statements held the highest means and lowest standard deviations among thirty statements on leadership practices. This suggests a strong agreement about the perceived leadership practice of modeling the way. Statement number 6 (I spend time and energy making certain that the people I work with adhere to the principles and standards we have agreed on) earned a low mean score of 7.77, which means that the leaders spend little amount of time and energy to ensure that the followers are able to adhere to the plan of action and regulations. Another statement in modeling the way, statement number 16 (I ask feedback on how my actions affect other people's performance), earned the lowest mean (7.46), which indicated that university presidents have a low focus on obtaining feedback about their behavior from followers to make the required changes in behavior.

The frequencies and percentages have also been calculated for the LPI category of modeling the way. A significant percentage of the respondents have scores ranging from 39 to 60. Kouzes and Posner (2012) stated that individual scores ranging from 52 to 60 were considered high and from 43 to 51 were considered moderate level, and scores ranging from 20 to 42 were considered low. Most participants (15 out of 26) scored from 52 to 60 , while the remaining 10 participants scored in the moderate level from 43 to 52 . Only one participant scored low at 39 . This means that the university presidents perceived that they engaged in this practice at high and moderate levels (see Table 4.5).

Practice three: Inspiring a shared vision. Inspiring a shared vision, the third practice of leadership was represented in Table 4.6. There were six statements associated with this practice that are ranked according to the highest mean score. Statement number 27 (speaks with conviction about meaning of work) indicates that university presidents' attention mainly centered 
Table 4.5.

Frequency Counts and Percentages of Specific Scores on Kouzes and Posner's Leadership Practice Modeling the Way from the LPI-Self Survey Completed by University Presidents.

\begin{tabular}{lcc}
\hline Individual Scores & Frequency & Percentile Ranking Level \\
\hline $52-60$ & 15 & High $(57.69 \%)$ \\
$43-51$ & 10 & Moderate $(38.46 \%)$ \\
$20-42$ & 1 & Low $(3.84 \%)$ \\
Total & 26 & \\
\hline
\end{tabular}


Table 4.6.

University Presidents’ Mean Leadership Practices Inventory Ratings for Statements Related to Inspiring a Shared Vision

\begin{tabular}{lll}
\hline LPI Statement Number & Mean & SD
\end{tabular}

Statement twenty-seven

- I speak with genuine conviction about the higher meaning

9.35

.797 and purpose of our work.

Statement twenty-two

$\begin{array}{lll}\text { - I paint the "big picture" of what we aspire to accomplish. } & 9.12 & 1.071\end{array}$

Statement two

- I talk about future trends that will influence how our work $\quad 8.77 \quad 992$ gets done.

Statement twelve

- I appeal to others to share an exciting dream of the future. $\quad 8.27 \quad 1.343$

Statement seven

- I describe a compelling image of what our future could be. $\quad 8.19 \quad 1.575$

Statement seventeen

- I show others how their long-term interests can be realized by $\quad \begin{array}{ll}7.58 & 1.578\end{array}$ enlisting in a common vision.

Maximum*10 
on emphasizing the meaning of work to facilitate the personnel in fulfilling their responsibilities with highest means (mean=9.35). Also, statement number 22 (I paint the "big picture" of what we inspire to accomplish) had a high mean score of 9.12. It shows that the presidents share the vision of the future in terms of short-term as well as long-term objectives. On the other hand, the mean value for statement 17 (shows others how their interests can be realized) was on the lower side $($ mean $=7.58)$, which suggests that the leaders had a lower degree of emphasis on helping others in pursuing their area of interest.

The frequency counts for each LPI score of inspiring a shared vision as perceived by the presidents of land-grant universities (See Table 4.7). The percentile ranking for inspiring a shared vision practice determined that the individual's high level ranged from 51 to 60 . The moderate level ranged from 39 to 50, while the lowest level ranged from 13 to 38 . Table 4.7 presented inspiring a shared vision scores ranging from 41 to 60 . There were 16 participants out of 26 in the high level range, while the remaining 10 participants represent the moderate level. This explains that the university presidents ranged between high and moderate levels for inspiring a shared vision.

Practice four: Challenging the process. Challenging the process is the fourth practice described by Kouzes and Posner (2002). There were six statements associated with this practice ranked according to the mean score from the highest statement mean to the lowest statement mean. In table 4.9, statement number 23 (I make certain that we set achievable goals) means that the presidents provide people with a set of realistic goals that can be achieved with the given time and resources. They had the highest mean of 9.04, which means that the university presidents set up objectives that are realistic and attainable. The lowest mean score of 7.81 is related to statement number 8 (I challenge people to try out new and innovative ways to do their 
Table 4.7.

Frequency Counts and Percentages of Specific Scores on Kouzes and Posner's Leadership Practice Inspiring a Shared Vision from the LPI-Self Survey Completed by University

Presidents.

Individual Scores $\quad$ Frequency $\quad$ Percentile Ranking Level

\begin{tabular}{lcl}
\hline $51-60$ & 16 & High $(61.53 \%)$ \\
$39-50$ & 10 & Moderate $(38.46 \%)$ \\
Total & 26 & \\
\hline
\end{tabular}


Table 4.8.

University Presidents’ Mean Leadership Practices Inventory Ratings for Statements Related to Challenging the Process

LPI Statement Number

Mean

SD

Statement twenty-three

- I make certain that we set achievable goals.

9.04

.916

Statement twenty-eight

- I experiment and take risks, even when there is a chance

8.81

of failure.

Statement eighteen

- I ask, “What can we learn?” when things don't go as expected. 8.58

Statement thirteen

- I search outside the formal boundaries of my organization

8.42

1.332

for innovative ways to improve what we do.

Statement three

- I seek out challenging opportunities that test my own

8.12

1.395

skills and abilities.

Statement eight

- I challenge people to try out new and innovative ways

7.81

1.550 to do their work.

Maximum*10 
work), which holds the notion that the presidents are less concerned abut motivating people to push beyond their normal performance, aiming to utilize their maximum potential, and using creative ideas in this regard.

In Table 4.9, the frequencies and the percentages related to the percentile ranking of the leadership practice "Challenging the Process" were presented. The frequency count indicates that the score of respondents ranged from 39 to 60 . Kouzes and Posner (2012) stated that scores from 51 to 60 are considered high, scores from 41 to 50 are considered moderate, and scores from 17 to 40 are considered low. There were 13 participants out of 26 whose scores from 51 to 60 , and 11 participants' scores were in moderate level from 41 to 50 . The remaining 2 participants scored in the lower level (39). This means that the university presidents perceived that they engaged in this practice at the high and moderate levels.

Practice five: Encouraging the heart. This practice is the last leadership behavior ranked by the university presidents of land-grant universities. The six statements were organized according to the highest mean score for each statement. Table 4.10 demonstrates the mean score of encouraging the heart leadership practice as presented by the university presidents of landgrant universities. The highest mean score was on statement number 25 (I find ways to celebrate accomplishment), which indicates that the presidents think up ways to acknowledge the achievements of employees and faculty members through holding different events. Statement number 15 (I creatively reward people for their contribution) received a low score of 7.65, which means that the presidents engaged less in offering creative rewards to people, but gave rewards that were commonly given to the personnel. Statement number 5 (I praise people for a job well done) also received a low score of 7.88 , which shows that the presidents in land-grant universities 
Table 4.9.

Frequency Counts and Percentages of Specific Scores on Kouzes and Posner's Leadership Practice Challenging the Process from the LPI-Self Survey Completed by University Presidents.

\begin{tabular}{lcc}
\hline Individual Scores & Frequency & Percentile Ranking Level \\
\hline $51-60$ & 13 & High $(50 \%)$ \\
$41-50$ & 11 & Moderate $(42.30)$ \\
$17-40$ & 2 & Low $(7.69 \%)$ \\
Total & 26 & \\
\hline
\end{tabular}


Table 4.10.

University Presidents’ Mean Leadership Practices Inventory Ratings for Statements Related to Encouraging the Heart

\begin{tabular}{lll}
\hline LPI Statement Number & Mean & SD
\end{tabular}

Statement twenty-five

- I find ways to celebrate accomplishments.

8.62

1.134

Statement twenty

- I publicly recognize people who exemplify commitment

8.54

and shared values.

Statement thirty

- I give the members of the team lots of appreciation and support for their contribution.

Statement ten

-I make it a point to let people know about my confidence

for innovative ways to improve what we do.

Statement five

- I praise people for a job well done.

7.88

1.505

Statement fifteen

- I make sure that people are creatively rewarded for their contributions to the success of our projects.

Maximum 10* 
do not commonly engage in verbal praise of the staff members and faculty when they perform their job responsibilities well.

In Table 4.11, the frequencies and the percentages related to the percentile ranking of the leadership practice encouraging the heart were presented. The frequency counts indicate that the scores of respondents ranged from 40 to 60. Kouzes and Posner (2012) stated that in case of scores of 53 to 60 are high. Moderate level scores ranged from 42 to 52, while low scores are from 15 to 41 . Only 8 participants out of 26 ranged in the high level from 53 to 60,15 participants out of 26 ranged at the moderate level from 42 to 52 , while the remaining 3 participants scored in the lowest level at 40 and 41 . This means that a majority of the university presidents perceived that they engaged in this practice mostly at the moderate level.

\section{Question two: Is there a significant difference in how land-grant university presidents} perceived their leadership practices across the five principles of LPI? If so, which practices are perceived differently among land-grant university presidents?

To answer this research question, an analysis of variance (ANOVA) has been computed. For this analysis of variance, the five dimensions reported the repeated values. There is no between-subjects factor for this analysis. If the analysis of variance yields a statistically significant finding $(p<.05)$, then a "multiple comparison" will be computed to determine which pairs of the dimensions differ significantly $(\mathrm{p}<.05)$. Thus, comparisons will be tested.

In Table 4.12, the value obtained through Wilks' Lambda Test (0.465) is significant as the sig value is 0.002 . A significant value less than 0.05 indicate a significant level of difference between the mean score of categories tested in research. In this study, the sig value suggests a significant level of difference in the use of five leadership practices by university presidents. The effect size for this difference is 0.535 (Partial Eta Squared). 
Table 4.11.

Frequency Counts and Percentages of Specific Scores on Kouzes and Posner's Leadership Practice Encouraging the Heart from the LPI-Self completed by University Presidents.

\begin{tabular}{lcc}
\hline Individual Scores & Frequency & Percentile Ranking Level \\
\hline $53-60$ & 8 & High $(30.76 \%)$ \\
$42-52$ & 15 & Moderate $(57.69 \%)$ \\
$15-45$ & 3 & Low $(11.53 \%)$ \\
Total & 26 & \\
\hline
\end{tabular}


Table 4.12.

Multivariate Tests (SPSS)

\begin{tabular}{llll}
\hline Effect & Value & F & Sig. \\
\hline Wilks' Lambda & $.465^{*}$ & 6.329 & .002 \\
\hline
\end{tabular}


To test the homogeneity of variance, a Mauchly’s test of sphericity was computed (See table 4.13). In this test, the significant value of 0.205 indicates there is no significant, so the variances among the practices are approximately equal. Then, pair wise comparisons have been conducted as follows to further understand the nature of these differences. In Table 4.14, it can be observed that significant differences exist between the leadership practice of enabling others to act and three other practices, namely, inspiring shared vision (ISV), challenging the process (CTP), and encouraging the heart (ETH). It is important to note that there was no significant difference between enabling others to act (EOA) and modeling the way (MTW).

In the phase of qualitative data collection, it became evident that some of the presidents were related; "Modeling the Way" with "Enabling Others to Acts" work together and cannot be separated. For example, in response to MTW, the respondents provided information that was related to EOA and vice versa.

Similarly, the participants viewed other practices, namely ISV, CTP, and ETH as a process, which is possible only after they had achieved EOA in conjunction with MTW. Thus, university presidents have emphasized using their cordial relationships with others to attain goals and objectives. Moreover, the lack of understanding between the different nature of EOA and MTW also resulted in no significant differences between the scores of these categories. The lack of difference between the leadership practices will be further elaborated in the section pertaining to analysis of qualitative data.

\section{Question three: How do university presidents of land-grant universities think they use leadership practices in their institutions as described by Kouzes and Posner (2002)?}

This question presents a detailed description of the five participants, the participant's narratives, and the major and minor themes that emerged from the analysis of the interview data. 
Table 4.13.

The Mauchly's Test of Sphericity

Within Subjects Effect

Mauchly's W

Sig.

Factor1

0.595

.205 
Table 4.14.

The Pairwise Comparisons among the Five Leadership Practices as Described by the University Presidents of Land-Grant Universities

\begin{tabular}{cccc}
\hline Factor & Factor & Mean & Sig.b \\
$(1)$ & $(1)$ & Difference & \\
\hline EOA & MTW & 1.731 & .561 \\
& ISV & $2.654^{*}$ & .038 \\
& CTP & $3.154^{*}$ & .012 \\
& ETH & $4.654^{*}$ & .001 \\
\hline
\end{tabular}

Based on estimated marginal means

*. The mean difference is significant at the 0.05 level.

b. Adjustment for multiple comparisons: Bonferroni. 
The interviews were first recorded and then transcribed by the researcher. To report the data, a "Constant Comparative" method was used as described by Maykut and Morehouse (1994).

For each question, the researcher inserted all the answers for all participants after identifying the participants as "president one, president two, president three, president four, and president five." Categories were developed according to the five leadership practices with each category consisting of themes and statements of the participants who provided how they used this practice. The researcher analyzed the interview questions and identified the presence or absence of the theme according to LPI category as follows: (1) Model the Way, (2) Inspire a Shared Vision, (3) Challenge the Process, (4) Enable Others to Act, and (5) Encourage the Heart. The data were arranged according to the existing common themes identified by the researcher, which provided a foundation of evaluating the data with reference to the principles of leadership provided by Kouzes and Posner (2002).

As the data analysis continued, the data were continually compared to previously categorized data. This led to a refinement of the data for greater clarity of understanding. The data were examined to search for relationships and patterns across categories. The results of the analysis are presented by leadership practice category. The resultant information is a compilation of the leadership practice of university presidents at land-grant universities.

Category one: Modeling the way. The whole idea of "Modeling the Way" is to provide a framework of values for the followers to see and model themselves (Kouzes and Posner, 2002). Several themes emerged with the practice of modeling the way when the presidents were asked the following question: "What do you think about the practice of modeling leadership? Can you tell me how you model leadership in your position as a president in your university?” 
One of the most important themes that presidents have agreed on is the importance of working as a team to make decisions through discussion about goals and objectives, and this can be achieved only leaders when have good interpersonal relationships and personal relationships with the followers. Presidents also need to be held responsible for their actions because their affect the actions of their followers. This suggests that university presidents consider interpersonal relationships among each other as commitment related to MTW practice. The following comments are from the interviewees:

President one said, “Sometimes you're a leader, but you follow others. Sometimes I make the decision. Other times, someone else might take the lead and actually help make the decision." President two stated, "We work on our goals and our objectives together and decide what actions to take related to those goals and objectives and what to do as a team." These statements are vital to the importance of teamwork and eventually reaching a common goal that everyone in the group has. President three said, "You have to have a good personal relationship with the people you are working with.” This represents the aspect of keeping good relationships among other faculty members and the president. This helps the group as a whole connect better with people because of having a better personal connection with them. Moreover, president 4 provides a good example of this practice. He stated:

Today we are in a snowstorm. Now, I have a chief of police and other emergency personnel that gather information and recommend to me what we should do in regards to closing school, the classes, and those sorts of things. I am the president and I'm technically the leader, but I listened very carefully to what they have to say and often time I follow their recommendations. 
President four has illustrated the use of seeking the opinion of other people and then making a decision that includes the perspective of other personnel as well. An effective leader does not dictate what needs to be done, but rather develops a plan of action on the basis of the point of view of the followers to secure commitment and motivation needed for implementation.

President five said, "I take responsibility for my actions and decisions and want others to do the same." President five has pointed out an important leadership behavior, by asserting that taking responsibility for one's own actions is essential to develop a sense of personal responsibility among followers. Instead of blaming others for mistakes, the president takes responsibility for the implications of his decisions, thus fostering a similar attitude among staff and faculty members.

Another important theme is represented by modeling the way through clarifying the values by setting high standards and communicating the values of how this can happen. Often followers need clear guidance and clarification along the way to achieve the goals and the objectives. Setting high standards guarantees that tasks will be achieved in a quality manner. For example, presidents may view modeling in a different manner. For instance, president three said, "I position myself in such a way that people understand what it is I value, how I answer questions, how I use data to make informed decisions, and you show them how to do that by examples.” President four stated, "I model leadership by making certain that I meet every expectation of my work and set a very high standard for dedication, integrity, and expectations." Modeling the way is also regarded as interrelated to the sharing of work values. This indicates that the president focuses on work standards as a framework through which the personnel can be guided. Furthermore, it also reflects the emphasis on setting an example for followers, by 
adhering to high work standards, thus encouraging them to follow the lead. Thus, presidents agreed that clarifying ideas and the process to the goal is needed.

Another theme discussed with the participants is that a leader is a "guide," and in that way, leaders can show followers how they practice being a role model. The notion of modeling the way is also perceived as similar to offering guidance to the faculty and staff members suggested by president one, "I don't typically ask people to do things that I'm not willing to do. I usually try to lead by example." He continued by stating how he represents himself as a role model: "It's through your speeches or through a panel of presentations or simply showing them how to prepare for board meetings."

Another responder (president two) said, "I wouldn't expect people to follow my instructions if I am doing the opposite of what I say." Also, president five indicated, "I have to make sure that people can look up to me as a guide. It also shows them that if I am doing certain things as a university president, they should also do the same." This indicates that the leader has to serve as a role model by illustrating desirable behaviors that people can adopt. Moreover, in circumstances where people are uncertain of appropriate behavior, the leader can serve as a guide for them. Therefore, leading by example has been a great way to show a group how to do things, and most would agree that it is the most accurate way to get the intended outcome of a project.

The last theme in modeling the way is the use of different leadership styles (situational, democratic, or autocratic leadership). The following comments demonstrated the abovementioned themes: President one stated, "Sometimes you have to lead autocratically and be firm. Other times you lead with a democratic process." President two said, "Modeling leadership really varies, and the type of leadership that you model depends on the type of situation that 
you're in." This suggests the notion that presidents in land-grant universities have their own distinctive views of what constitutes modeling the way. Some of the presidents may deem it as a representation of situational leadership style, where the leader chooses to use authority or participation as a leadership style.

Category two: Inspiring a shared vision. Inspiring a shared vision is the ability of a leader to imagine the future and clearly articulate the vision to others, which enables the leader to gain the followers' support and belief in the vision. A leader can more clearly see how people behave towards one another by having strong values and beliefs of how cooperation could achieve the shared vision (Kouzes and Posner, 2002). The following themes have been identified when the presidents were asked, "What do you think about the importance of sharing vision as a president of LGU? And how do you communicate a shared vision with others?"

One major theme emerged with this practice: a leader must communicate and collaborate to build a shared vision (through the use of written and verbal communication with different group members), use vision statements, use meetings to inspire others, and discuss the vision. The aim of communicating is to not only determine the vision, but also look at the way of achieving the vision. The participants made the following comments:

President one stated, "I work with them on the development of the strategic plan and am able to share it with the people who can help in making it a reality." President two said, "I think it's important to communicate the vision consistently with external stakeholders as well as internal stakeholders. I communicate visions through meetings with the entire university campus. I meet with the different departments, different units on campus. I meet with the community members. I meet with a variety of people on a regular basis." He further stated: 
I talk to the leadership on campus about the direction that they think is appropriate, such as the vice president and the deans to make sure our direction is similar. If they're different, we talk about how they are different and how we can bring them closer together.

Clearly, university presidents used the communicating method not only to provide a common vision, but also to determine how they are going to meet that vision. President three stated:

They create their own vision of the future. I don't tell them to do anything. We collaboratively determine what the plan is. We negotiate the strategic plan. They bring to me what they think the unit goals ought to be for the year. They provide the justification for how those unit goals fit into the goals of the university for that particular year. If they do it, they own the vision. Then they understand it. They embrace it.

President four had similar views on the manner and said, "I communicate in a variety of ways, both in terms of continuing conversations large and small with the University community and beyond, but also through a series of written communications and declarations." By communicating thoughts and ideas, the plan of the shared vision comes together, and having the president work on the plan with them is also an important factor of seeing eye-to-eye on the same vision and makes it easy to achieve that vision. Thus, it is vital to determine a shared vision, meaning everyone is on the same path to the goal and can see the same success. This is why it is important for leaders to communicate to their followers, what their thoughts are and how things can logistically come together for the goal.

Another theme is to know what people are passionate about and to use the vision to clarify the role of people and to discuss setting up the vision. This goal can be achieved through 
meetings with different people inside or outside the organization. It helps leaders to enlist others by knowing their interests and their passions. This is again where communication plays an important role in the shared vision. Here the presidents discussed how they enlist others and engage them in conversation in order to achieve the results they want. They focused on their mission and at the same time projected their passions through a productive manner.

President one said, "You have to actively engage them, and you have to value their opinions. You have to ask for their opinions or you can't come with prescribed or preconceived notions. You are inviting them to join you and proving the vision, and if you can do that, you're committing people that are very loyal." President two also stated, "I bring them into the meeting and talk about things that departments are doing. I work with people to see what gets them excited, what they are passionate about. For example, if they're passionate about international education, then we might talk about how that might fit into the vision." President five said, "I never impose my own ideas on others without considering their input. They are invited to be a part of the vision development. People are provided with a clear vision of who we are and how they can contribute to being a part of our success." These quotes illustrate how inspiring a shared vision by presidents can encourage the faculty and staff to work together for common goals.

Category three: Challenging the process. This category discusses the leader's emphases on seeking out and accepting challenges, as well as leaders who challenge the process by recognizing and supporting innovative ideas, experimenting with new systems, and taking risks to bring about change (Kouzes and Posner, 2002). The researcher asked the presidents, "What does it mean to challenge the process at a land-grant university? How do you show others that the status quo must be challenged?" The themes identified are as follows: 
One of the most important themes associated with challenging the process is being open to change to enable leaders to achieve success by being creative and innovative, seeking ways to enhance efficiency, experimenting with new ideas, challenging the status quo, and using various creative solutions. Inevitably challenges can lead to better outcomes and in some cases, opportunity. This opportunity is not only for the leader, but also for the followers and the institution as a whole. The following comments illustrate the theme.

President one said, "We develop a strategic enrollment plan for recruiting as an example of giving an opportunity for different types of students in enrolling and service the university as well." He continued:

Right now for example, the student demographic is changing for the United States. With more diverse people, the challenge is to help the people be ready for $21^{\text {st }}$ century jobs. We turn those challenges into opportunities, and opportunities can help us become successful as an institution.

Also, president two said, "We're always looking at more ways to become more efficient, and that's part of it. We manage it by looking at the research and looking at the outcomes we hope to get and build a hypothesis on what we think we know." He provides an example of the importance of goal to meet the challenge. He stated:

We have partnerships in our agriculture program with a company that buys a lot of soybeans, and we are looking to do research that enables farmers to produce more soybeans in our region so that the company does not have to go to the other side of the United States to buy soybeans. So we're doing research on how to grow soybeans in this climate, and that is an innovative approach and a challenging process of what a landgrant institution does. 
President three also stated:

Doing what was done in the past will not allow us to succeed, individually or institutionally. I will always be open to change and to try different things, to try to be creative and innovative so that we can do more for our communities and our society. President four said:

You must be willing to change, and to challenge the status quo. Without doing so, I believe it is almost impossible to succeed. My favorite quote comes from General Eric Shinseki: "If you don't like change, you are going to like irrelevance even less." I live by that standard.

President five said, "I think it means doing something different, rather than following traditional methods. We keep focus on introducing new means of teaching such as technology." Also, president five said, "To meet the financial needs of running the university, we had to come up with some new sources of funding." These sentences emphasized the role of university presidents in using their leadership skills to meet the challenges faced by the organization, especially in these difficult economic times.

Another theme identified was that leaders should be willing to take risks and accept consequences to avoid stagnation, but they also need to avoid high-risk opportunities. Furthermore, responders described using a pilot method as a way of testing before implementation to avoid high-risk consequences. Although risk taking can often bring great outcomes, it may also bring forth non-desirable ones. The high-risk opportunities are best avoided in a leadership position, and the university presidents spoke on the manner. President one stated, "You have to be willing to take a risk, and you have to live with consequences of those risks. But you won't learn unless you're willing to be a risk taker." President two stated, 
"We have to understand that mistakes will be made as we try to improve on what we do. You know, there will be mistakes and it will happen."

President five stated:

I wouldn't be taking a high-risk opportunity because you know doing a business is different from running a university. We take risks such as doing things differently, introducing new ways of achieving objectives, and creatively responding to the problems we are facing. If we don't take risks, we will become stagnant.

President three stated:

We do something in a pilot study to make sure that we are able to make course adjustments before we go live in a full-blown initiative. An example would be like last year. We experimented with our freshman introductory biology courses on an early alert system so that students who were not performing up to standard given their capabilities, we have the ability to know who they were early using this electronic system. We also had to experiment with how we responded once we had the information available of students who were not attending class, or having difficulty early in the class. So we ran that for last fall and made some adjustments. Then we'll go live with doing that for 2013 with 100-200 level courses using the electronic system.

Thus, small steps in the experiment could reduce the risk and increase the success. Presidents knew that the best leadership approaches to avoid high-risk experiments are these pilot study examples.

Category four: Enabling others to act. Apart from offering inspiration to people, a person who is able to guide a group towards a positive course of action is also a source of effective leadership. "Enabling Others to Act" consists of ideas such as teamwork, trust, 
confidence, and empowerment (Kouzes and Posner, 2002). The researcher asked the participants, "What do you think about the importance of enable others to act independently to fulfill a common mission? How do you enable others to act to fulfill a common mission?" The following themes emerged:

One important theme in this practice is the development of mutual trust and confidence as a way to foster collaboration among followers. The ways that presidents offered support are through a great deal of communication and encouraging teamwork. The following comments from the participants support this point: President one said, "An environment where they feel that they are important, like they are a part of a team, and they are being listened to." Also, President two stated, "You foster cooperation by getting people involved, getting people engaged, and listening to their perspectives." He also stated, "It's about having that conversation, and it's about listening to the different perspectives and points of view and keeping the focus on the goal and the different points of view." There has to be a lot of communication, and you have to be in tune with the goal to be successful in achieving the organizational goals.

Another comment came from president three, "Each person has annual goals that they and I developed." President 5 had the same thought: "I trust the faculty members to make right choices, and I fully support them in discussing the different alternatives with each other." Thus, including everyone in the decision-making helps to motivate followers and feel as if they are really making a difference. There is no substitute for this confidence of thinking you have really affected a matter that was subject to change.

President four had similar views, but was very keen on keeping organization as the primary way to handle off-topic statements. President four said, "I believe in a matrix organization, which allows everyone to act independently but at the same time, do so within a 
common context to reach the university goals.” President four said, “ A strong matrix

management system in which there is sharing and independence is enormously important." This is an important reminder that a leader is in fact vital to reaching a goal. Getting off-topic can be easy, but it can also stray from the path you intended to take.

Another theme that participants agreed on is the role of leader as a facilitator in the decision-making process. Instead of imposing decisions on employees, the employees can be guided through decision-making process. A president also empowers the followers through providing autonomy to achieve goals using individual thinking, being open to suggestions, encouraging feedback, belief in president. It is important to remain respectful of the input that everyone has. Several comments support this theme. President one said:

Part of my job is to enable people to think, to see what the goal is, but not to tell them exactly what stones to step on. What's important, as a leader, is to get them to see the end-point of the goal and then turn them loose to get there.

While president two had the same perspective, he stated:

Ideally, you want all people affected by a change to push most of them to be involved to implement the change and to some extent be involved in the decision making so that they really buy into the change that we're trying to promote. For example, sometimes you might speak to a colleague to give them a particular goal. As opposed to prescribing it to them, you'll let them decide how to reach that goal.

President three also had similar views on this theme, adding, "My form of support is making sure they have everything they need to do their work. If there are any obstacles or impediments, it's my job to remove them." President four said, "People need to be able to think and make sound judgments on their own. I am open to all suggestions as each idea is important 
to me." President five also commented, "When the faculty members face problems, I prefer not to hand them a solution directly. I want them to think about the issue and develop a feasible solution on their own." Leaders often listen to their group members hoping the followers will stay on track; however, that is not always the case. Although it is important to have everyone's input on the subject at hand, it is also essential to keep in mind the goal and how what everyone is saying translates to reaching this goal.

Category five: Encouraging the heart. This practice refers to the ability of a leader to be a source of encouragement and support for the followers as well as someone who celebrates their achievements. The leader offers encouragement to followers by focusing on their achievements and offering words of encouragement and appreciation (Kouzes and Posner, 2002). The researcher asked the participant, "How do you encourage the heart in your university?" Two common themes in this category are as follows:

The first theme is that encouraging can be done individually or as a group through different ways such as sending birthday cards, giving monetary rewards, giving out t-shirts, or sending a signed note of acknowledgement, not to mention giving verbal appreciation. The following comments demonstrated this theme: President one said:

I make sure everyone is recognized for the contributions that they have made, individually and as a collective group that has moved us forth this year. Sometimes it's something as simple as sending birthday cards to everybody on their birthday that I handwrite and put a little note on.

President two said, "Money isn't always the best encourager. People work for the recognition. They work to make a difference." President three said (in regards to social gatherings and rewarding faculty), "We have parties at my house; we have dinners. We give t- 
shirts out on campus." President four said, "I constantly communicate with others providing thanks and encouragement." President five said, "I believe a bit of encouragement can make the staff and faculty willing to put in extra effort to do their jobs."

Another theme is the social events and get-togethers, feeling like a family, recognition events, peer-reviewed awards, and annual performance reviews. Having gatherings outside of work can help build a relationship between faculty members as well as between the leader and their followers. President one said, "You can have celebrations as a group, whether it's getting our accreditation or opening a child care center. We have parties at my house. We have dinners. We give t-shirts out on campus."

President two said, "We have a lot of events where employees get together and get to know each other socially, and they get to work together. We bring everyone together so that we become one family." President three stated, "There was an event called 'Celebrating Faculty Excellence.' We recognize the most accomplished of our faculty and we have a department head award. All of the awards are peer-reviewed."

President four specified, "We have annual performance review of faculty and staff members. The top performers get a signed note from me." In sum, these sentences explained that presidents recognized the importance of celebrating the accomplishment.

The common themes identified above and the statements related to them provided by presidents of land-grant universities provide insight into the different manifestations of leadership practices as described by Kouzes and Posner (2002). However, there are two major observations in this case: One observation is that the majority of the respondents agreed that the leadership practice of "Enabling Others to Act" is the main practice; without this practice, they cannot achieve the outcomes of other practices. However, the participants connect enabling 
others to act with the leadership practice of modeling the way. The presidents were not able to distinctively understand the differences between enabling others to act and modeling the way as they described these two practices interchangeably. The following comments support this observation:

President one said, "I do believe that the practice of enabling others to act is very important." When he answered the question related to MTW, he commented, "You have to actively engage them and you have to see them as individuals. You have to give people feedback on their ideas and ask them to help you."

In answering the question related to EOA, president two explained, "Yes, I think it's important to do that." Then president two said, "Well, they have to believe in what you're doing. I mean, if they don't believe in what you're doing, then it's very difficult to get their support." President three stated:

A leader can't make a decision and decide that it works the same for everybody. It does not. People work in their own ways. They process in different ways, so what's important as a leader is to get them to see the end-point of the goal and then turn them loose to get there.

President four said in responding to the MTW question, "The most important is developing a special interpersonal relationship with people before any of this will work." $\mathrm{He}$ continued, "Modeling the way could not be achieved if we don't clarify our values and beliefs. This only can happen if we have strong relationships among each other."

In response to EOA question, president five specified, "It is very important. People need to be able to think and make sound judgments on their own. You have to empower others to give leadership that enables them as individuals to be successful in their own activities." 
The second observation in this study is that all participants attributed the success of their leadership to all five practices working together. "In one way, they are almost all related," said president one. Another responder said, "We cannot separate these practices. We have to look at them as a "PROCESS." Here are some comments from the presidents:

President one stated in response to the question related to MTW, "We do process mapping. We do modeling when we have a good relationship with each other. Then we follow that vision, and we lay out how you translate vision into action together." This quote connects MTW, EOA, with ISV. When he answered questions related to ETH, president one stated, "It is easier for us to move together in sync and as a team of people in terms of our growth and in terms of changing the role of the university. We celebrate to recognize our achievements together as a team." This explains how all five practices work together as a chain and encourage the heart to celebrate the achievement they agreed on at the beginning of the process. Also, president one stated, "My job is to motivate them and to keep them inspired and even to recognize them when they achieve their goals." Actually, this statement connects enabling others to act with modeling the way, inspiring a shared vision, and encouraging the heart.

Another comment was made by president two in responding to the question related to EOA, "If people see their ideas about a process, they're more likely to achieve that result." Also, president two stated in response to ETH:

The outcome has been that we know each other better, and we're able to work with each other better because we know each other at work and we know our families. We respect each other, and we care about each other. I think that makes a difference. It motivates people to go back to their work and do better because we recognized them as an individual or as a group." 
These statements connect enabling others to acts and modeling the way with the challenging the process.

Another statement made by president two connects MTW, EOA, and ISV. He stated, "Trust comes with building your relationship and listening and talking and having respect for everyone's ideas and getting people involved in the process of vision making."

President three was of the opinion that "the role is not this complex. I think they make a whole lot of things out of a very simple process." President three answerers connected MTW, EOA, and ISV with CTP. He stated:

The first thing is to develop very good personal relationships, and then you join the vision. It's not my vision. It comes from the heart and soul of the working relationship that you have with your team. So if it's developed from within, you don't have to communicate it.

Moreover, in response to the CTP question, president two stated, "You engage in a process in which they understand that to go forward doing what was done in the past will not allow them to succeed". He also explained how CTP, MTW, ISV, and EOA are all related to each other as shown in the following statement:

If you don't have a plan, all you make are hard decisions such as eliminate some programs, cut faculty, size down, and so on. That enables you to build from a new base if you do that in a collaborative fashion so that the institution is still owned by that faculty in the department heads and the deans that actually create the opportunities for students and give leadership to research.

In response to the question related to ISV, president four connected ISV with CTP when he stated, "It's a challenge to meet these visions, absolutely. But a vision is supposed to be 
challenging." President four made another comment, he said: "The role of leader is not only to lead but also to encourage others to lead."

President five stated, "For me, leadership is about a process. You can't just divide it into different practices and categories." He said, "We all work together towards the common vision. We encourage team work, but also support people in realizing their individual potential." However, when president five described his role in challenging the status quo, he said, "I actively participate in the event. When people see me directly being a part of something, they get more motivation to be part of it." These sentences actually related ISV and EOA with CTP.

President five, answering the question related to ISV, stated, "I encourage people to celebrate small successes. It helps them to reinstate the focus on vision.” This sentence related ETH to ISV. President five continued, "It helps people in staying together, working as a team, facing difficulties, and supporting each other." When president five described the outcome of ETH, he related it to the outcomes of other practices: EOA, MTW, and CTP.

Discussion of the findings and conclusion of the study are presented in the next chapter. 


\section{Chapter 5}

\section{Discussion, Conclusion, and Implications}

The purpose of this study is to examine the leadership practices of land-grant university presidents as described by Kouzes and Posner (2002). Furthermore, the study aimed to find whether or not the university presidents viewed their own leadership practices differently. A total of 26 LPI-self surveys and 5 interviews were conducted to answer the research questions. The research process used a blend of quantitative and qualitative research approaches known as a mixed method to expand the understanding of the leadership practices of university presidents at land-grant universities in the United States.

This chapter focuses on elaborating on the results generated through quantitative and qualitative methods, as shown in Chapter four. A detailed discussion about the findings of the study offers supportive evidence from available literature. There are three sections in this chapter. The first section provides a conclusion of leadership practices of university presidents from the LPI self-survey, followed by the discussion of emergent themes associated with each practice. The second section provides a unique pattern of the differences between the commonly used leadership practices and the utilization of such behaviors by presidents in land-grant universities. Finally, the researcher provides some implications for future study.

\section{Section One: The Leadership Practices of Presidents at Land-Grant Universities as Reported in the LPI-Self Surveys and Interviews}

Kouzes and Posner (2002) identified five leadership practices: enabling others to act, modeling the way, inspiring a shared vision, challenging the process, and encouraging the heart. Question number 1 examined the leadership practices of university presidents at land-grant universities using the LPI-self surveys. The results show that presidents at land-grant universities 
are perceived as practicing all five leadership principles. Kouzes and Posner (2002) have developed these practices from the philosophy that a leader who is successful and effective must use these principles to gain positive outcomes. Moreover, Kramer and Swing (2010) contend that the role of a university president spans various activities, from managing the faculty and staff at the campus to providing direction to the academic institution. As a leader in a university, the presidents have to fulfill various roles and responsibilities that are associated with their position. They are required to enforce the mission and strategy of the institution as well as handle problems and challenges. They have to respond to the needs of internal and external environment as a leader. According to Mills (2004) an effective leader is the one who is able to adopt different leadership frames according to the need of the situation. These leadership frames are: political, human resources, bureaucratic and symbolic. For example, weather turbulence and on campus violence are two different scenarios, which require different set of responses from university presidents. Economic crisis is also a challenging situation that has forced the presidents of LGUs to use their leadership skills to maintain the functioning of the institutes despite the decline in funds (Nicholson, 2007; Green, 2008). The university presidents also had to maintain high level of motivation among the staff members.

Fullan and Scott (2009) indicated that as the dynamics of the $21^{\text {st }}$ century change, the university president's roles and responsibilities have also shifted. Instead of focusing on administration, presidents focus on issues such as changing needs of students and the resultant alterations in the academic curriculum and objectives. Leadership has become a mandatory skill for university presidents. For today, academic institutions need guidance to respond to the rapid globalization, increased dominance of technology in human life, and additional emphasis on development of professional competence among students (Padilla, 2005). 
Brown (2001) suggests that the application of the five principles of leadership can help an organization develop leaders who focus on the growth and development of individuals and organizations as a whole while taking long-term perspectives into consideration. It has been further asserted that the application of these principles in the workplace can give rise to improved performance of a team (Brown, 2001). Similarly, within an educational institution, the application of five principles of leadership can facilitate the university presidents to manage the staff and students during difficult situations.

According to (Bush et al (2010) leaders may use one particular leadership style more as compared to other leadership styles. This notion is consistent with the results showing that the highest score was obtained for the category of enabling others to act. This finding suggests that the majority of presidents focused on the practice of enabling others to act as a predominate leadership practice. The second highest score was obtained by the leadership principle of modeling the way. Third ranking was obtained by inspiring a shared vision. Challenging the process was at fourth rank and encouraging the heart was at the fifth position. This ranking (in descending order) is based on the mean scores obtained by leadership practices of university president.

Enabling others to act. Enabling others to act consists of active listening, supporting decisions of others, treating people with respect, focusing on interpersonal relationships, and providing individuals with alternative courses of action to select from to attain the objectives. Enabling others to act obtained the highest mean value in quantitative data, and the qualitative data have also supported this notion as a majority of the presidents have considered it to be a platform on which the human resources can be effectively facilitated. . Many researchers who have used LPI survey suggested that enabling others to act is the mostly used practice among the 
participants (Aaker, 2003; Anderson, 2004; Bauer, 1994; Castro, 2003; Du Plessis, 2008;

Hempowicz, 2010; Orman, 2002; Oliver, 2001; Plowman, 1991 \& Rozboom, 2008).

Clearly, presidents not only have emphasized the need to engage in behaviors that support other people to act in a way that helps them achieve goals, but also fostered a sense of independent thinking and decision-making. Krill et al. (1997) studied the leadership practice of enabling others to act specifically. It has been found that the leaders using the set of behaviors included in the category of enabling others to act participate in endeavors that facilitate the faculty members to fulfill the designation tasks more effectively. It has also been emphasized that such leaders use other behaviors that focus on the objective of enabling others such as serving as a source of inspiration and motivating to enhance performance. Agard (2011) stated that one of the prime responsibilities of a leader is to help the personnel engage in activities that direct the organization towards the achievement of common goals. The university presidents fulfill the leadership role by demonstrating similar behaviors.

The role of university presidents is to support the development of mutual trust and confidence as a way to foster collaboration among followers. Presidents offered support through communication and encouraging teamwork. Presidents rely heavily on effective communication and openness to other ideas to establish strong interpersonal relationships. They explained that building strong relationships with followers is a first step a leader needs to consider in achieving ultimate goals. Padilla (2005) asserted that university presidents could not be successful or make the academic institution excel unless they are able to establish effective communication with employees, students, funding sources, etc. The university presidents understood that collaboration and mutual trust are the tools to achieve organizational goals. Bauer (1994) also supported this notion, by suggesting that inspiring the staff members through communication is 
one of the essential skills of university presidents as reflected through the element of inspiring a shared vision.

Moreover, the role of university president as facilitator as a way to empower individuals was another point made by the participants. Kouzes and Posner (2002) illustrate that the ability of a leader to provide people with a sense of empowerment enables them to participate in activities that lead to the attainment of common goals. Presidents described the ways they used to empower their followers through involvement in the decision-making process, providing autonomy to attain goals using individual thinking, and being open to suggestions. Thus, presidents understood the importance of empowering followers to achieve a common goal. Presidents believed that the organizational goals could not be achieved without strength from others, such as involvement in the decision-making process.

Modeling the way. This practice ranked in a second order according to the LPI-self survey. However, the presidents connect modeling the way with enabling others to act when they explained the meaning of modeling the way. Obviously, presidents understood the power of modeling the way, but the power is strong without achieving the outcomes from enabling others to act. This explained why modeling the way ranked in the second order after enabling others to act. Brown (2001) has illustrated that modeling the way can be successfully used by the leaders in HEIs to support the strategic plans of the institutions. This practice will enable leaders to improve the effectiveness of their management of followers. Thus, the result demonstrates that university presidents were significantly focusing on the leadership philosophy, using it as a guideline to interact with the faculty and leading the educational institution.

The interviewees who regarded the clarification of values and future direction as the basis of organizational success have presented a similar notion. Presidents agreed that it is important to 
work as a team to build decisions through discussion of goals and objectives while having good interpersonal relationships among each other. A president's actions clarify the values by setting high standards and communicating the values of how this can happen. Often, followers need clear guidance and clarification along the way to achieve goals and the objectives. Setting high standards guarantees that those tasks being done will be achieved in a quality manner. Eden and Shani (1982) demonstrated that leaders who set high expectations of followers achieve a positive attitude and highly motivated employees by encouraging them to do their work in a timely manner.

Moreover, the university presidents made an effort to ensure that they delivered what was promised to the personnel. Middlebrooks and Allen (2009) indicate that a leader in HEI needs to manage the institution by portraying the behavior for followers to adopt. A university president displays behaviors and actions that are readily incorporated into the behavior of the administration and faculty members. This ability to follow the commitments develops an increased level of trust among followers. On the other hand, Chang (2005) explained that an effective leader is the one who is successfully able to activate individual as well as group motivation. Presidents need to spend more time and energy with followers, asking for feedback on their actions to make sure that their work was developed according to the standards agreed on.

Finally, university presidents indicated the use of different leadership styles. Pounder (2001) also observed that transformation and transactional leadership practices could be utilized to gain benefit from the different modes of leading the followers. Similarly, Strange (2005) stated that with an increase in the focus of leadership regarding group performance, the effectiveness of transformational leadership has also been highlighted. The principles of leadership outlined by Kouzes and Posner (2002) seem to be strongly linked with the qualities of 
a transformational leader. Therefore, the application of these principles in the workplace can give rise to improved performance of a team. Presidents utilized different leadership styles according to the needs of their organizations, raising the performance of leadership and leading to success and fulfilled the goals.

Inspiring a shared vision. Kouzes and Posner (2002) define "inspire a shared vision" as the ability to imagine the future and clearly articulate the vision to others, thus enabling the leader to gain the followers' support and beliefs in the vision. Interestingly, the result indicates that ISV was ranked third with presidents of land-grant universities, while ISV was last in previous research samples using LPI surveys (Aaker, 2003; Anderson, 2004; Bauer, 1994; Castro, 2003; Du Plessis, 2008; Hempowicz, 2010; Orman, 2002; Oliver, 2001; Plowman, 1991 \& Rozboom, 2008). This suggests that university presidents of land-grant universities emphasized the meaning of work to facilitate the personnel in fulfilling their responsibilities to meet the vision of land-grant universities more than any other leaders in higher education sectors. Presidents had a sense of what is the most ideal outcome of their goals and practices as well as a structured definition of what to do. Nicholson (2007) emphasized that leaders must be inspirational and gaze across time to see valuable opportunities that are in store when they arrive at their destinations.

Moreover, university presidents explained the necessity and the implications of sharing the vision, the effect of having a shared vision, the inclusion of personal interest of the personnel in formation of plans and deeming it as a part of organizational culture. Safrit et al. (2004) emphasized the need to train university presidents to inspire others and effectively develop a vision that is mutually agreed upon by faculty and employees. It is further noted that a good 
leader does not force his or her own ideas on the employees, but obtains ideas from them and thinks about how to integrate them in the plan of action.

The presidents also agreed to speak about the essence of working in the university, linking the position of faculty with the future output and performance of the academic institution. Christ (1999) noted that presidents play an integral role in actualizing the vision and directing the university towards progress. However, the statement related to enlisting others in pursing the common vision had a low degree of emphasis among the participants. The followers must believe that the leader has their interests and their needs at heart and can relate to their ideas. Therefore, presidents should be able to imagine and portray the future responsibilities in such a way that followers are attracted toward their perspective and feel inspired to be part of the leadership process (American Institute of Higher Education, 2011).

Challenging the process. The university presidents have reported that they emphasize the need to set goals that are realistic, thus increasing the probability of attaining of the goals. For example, the financial crisis has altered the availability of funds for university presidents; in this case, as a leader, the president has to focus on setting goals that can be achieved despite the limitations of resources. London (1995) asserts that planning and goal setting are key responsibilities that entail the use of proactive thinking and behaviors. University presidents have illustrated the use of long-range thinking, motivating the faculty to work towards the goals.

Considering an economic crisis, land-grant universities with many budget reduction decisions must be able to survive and meet the future vision. University presidents must cope with institutional changes and use their leadership skills to make difficulties decisions that help their institution survive in a time of economic challenge. University presidents are required now to develop skills pertaining to handling the financial, human and public relations aspects of being 
the head of a university, thus requiring a different set of skills than what was needed in the initial phase of land grant universities (Rozboom, 2008).

One of the main themes in challenging the process was related to taking risks by trying out new ideas. To enhance the degree of effectiveness of the faculty members, the university president encourages the use of new ideas and creative notions. It also helps the university presidents to avoid the pitfall of stagnation and to move the academic institution towards progression. Iskander (2008) has noted that university president use and also encourage the use of advanced technology by faculty to conduct classroom lectures. It not only strengthens the position of the university, but also helps it in improving its overall performance.

Another important feature of this practice is that university presidents are still willing to take risks and experiment, even when they risk failure. They know that challenges should be made in order to achieve the goal. Kouzes and Posner (2002) explain that leaders know that positive change involves experimentation and risk-taking. This is important because without taking a risk, it is impossible to know what else may lie ahead such as opportunities and possible greatness that comes in part by exerting effort through challenges. Kouzes and Posner (2002) discussed that leaders understand that experimentation and taking risk are learning processes that can lead to success or failure. In doing so, a president could uncover some newfound goals and opportunities. Presidents search for opportunities to change the status quo, and they look for innovative ways to improve their universities.

However, presidents emphasized less trying out new and innovative ways of their work. They are willing to take or challenges, but with caution to avoid high-risk consequences. Describing how presidents could proceed with high-risk decisions, Goodman (2012; p. 13) described a leader as a "gambler." Leaders are taking high-risk ideas as a way to move into the 
future. It is a key for effective leadership. However, the author suggests a better way to handle high-risk consequences especially when the organization had faced pressure already such as economic challenges. The leader should involve more people in the decision-making process to reduce the possible risk involved. Also, according to Kouzes and Posner (2003), effective leaders need first to try small experiments for a large project in the form of model sites, pilot studies, and demonstration projects as a way to reduce high-risk consequence from their decision. Thus, leaders could prevent many problems and enhance chances for success.

Encouraging the heart. The land-grant university presidents were found to be focusing on the leadership behavior of celebrating the accomplishments. The leader offers encouragement to followers by focusing on their achievements and offering words of encouragement and appreciation (Kouzes and Posner, 2002). University presidents use a variety of methods to celebrate the accomplishments, such as sending concrete messages in birthday cards and signed notes of appreciation. At the same time, verbal acknowledgement of the effort and appreciation for the job done well were observed in the study. Madsen (2008) presented views about use of acknowledgement and appreciation by female university presidents. It has been stated that the use of rewards is utilized to enhance the level of motivation of the individuals who are rewarded. Therefore, university presidents offer acknowledge and praise achievement to encourage personnel and engage them in the same behavior in the future.

Also, university presidents recognize the importance of celebrating the success of individuals through get-together events, recognition events, and award ceremonies. Some presidents acknowledge good performance with faculty award ceremonies and leaving signed notes. Another interesting finding in this regard is that a low number of presidents considered using creative rewards as a means of reinforcing positive behavior among the personnel. 
Langone (2006) described this practice as a way to enable leaders to be a source of confidence for their followers.

\section{Section Two: Leadership Practices Model of University Presidents at Land-grant}

\section{Universities}

The second area of research concerned the differences among the land-grant university presidents in terms of the use of leadership practices of the LPI self-survey. The quantitative data clearly indicate the differences among the respondents through the application of ANOVA and Wilks' Lambda Test. The pair-wise comparison shows that the university presidents perceive the leadership practice of EOA to be different from the other leadership practices of ISV, CTP, and ETH. On other hand, the university presidents were not able to establish a clear distinction between the practices of EOA and MTW, considering them interchangeable activities; however, they are distinct behaviors in reality.

Pounder (2001) suggested the existence of a significant relationship between the leadership practices adopted by the leader of an academic institution and the resultant degree of success of the institution. The respondents in the study shared during the qualitative interviews that the integration of the five practices of leadership as identified by Kouzes and Posner (2002) definitely helped them in retaining their level of success despite difficulties and challenges from the external environment.

Moreover, Bensimon (1989) observed the differences among the leadership practices of dealing with the faculty and employees. It has been found that the tenure of the presidents seems to have a significant influence on the use of leadership skills. In cases where a university president is more seasoned, the usage of multiple leadership skills is evident. The presidents 
selected in the current study had a great deal of expertise in their domain. Thus, they were able to understand the needs of the faculty and employees and respond to them accordingly.

As a result, a unique pattern was established from the responders related to leadership practices. As seen in Section one, the majority of presidents agreed that the leadership practice of "Enabling Others to Act" is the main practice; without this practice, they cannot achieve the outcomes of other practices. "Educational leaders who acknowledge that human interactions are basic to our lives, to the creation of meaning, and to the development of understanding are more likely to take full account of the why, who, what, where, and when of schooling" (Shields, 2006, p.76). In this context, the view of leadership originates from the ability of the university president to form good interpersonal relationships with people. It has been further argued that other practices seem to be meaningless if the leader is not able to form effective relationships with people. For example, president four said, "The most important is developing a special interpersonal relationship with people before any of this will work." Simply speaking, presidents believed that if a leader does not have strong relationships with the followers, they could not work as a team and enhance the achievement of the organizational goals. The university presidents also seem to regard EOA as the most important practice, deeming it as a key force that facilitates the application of other practices. Therefore, this perspective has resulted in a high score for EOA.

Although "Enabling Others to Act" was important, they could somehow not detach it from the concept of "Modeling the Way." Presidents have discussed the importance of enabling others, while the interview question was related to modeling the way or vice versa. However, presidents are clear about the meaning of the two practices as seen in Section one, but they described the two practices as working together and not separated. For instance, President four 
said, "Modeling the way couldn't be achieved if we don't clarify our values and beliefs. This only happens if we have strong relationships among each other." Presidents understood how important it is to build a good personal relationship through actions that demonstrate what their values and beliefs are. Bush et al. (2010) have explained that the role of a leader does not simply define a person who provides direction to others, but it encompasses other factors as well. The values that a leader holds are manifested through their actions. Other studies indicated that an effective leadership style occurred within the human resource frame. This result indicated the importance of building good relationships between leader and follower as the heart of organizational success (Drummon, $2011 \&$ Mills, 2004).

The second part of the leadership model is that all of the presidents concluded that all of the practices were important and one could not work without the other. Presidents agreed that leaders should look at these five practices as a "PROCESS." Parolini et al. (2009) agree with the principles of leadership by suggesting that there is a strong link between those five principles and the qualities attributed to servant leadership. Because a servant leader has a strong focus on helping other people in such a manner that they achieve their goals and targets, the five principles of leadership support this process of facilitation. McMurry (2010) suggests that the role of university presidents shifts from a traditional and bureaucratic leadership model to a more democratic leadership style such as transformational leadership. He found that the relational leadership model is the central theme among the university presidents.

Moreover, an effective leader would be focused on the relationships among each other by having strong values and beliefs of how the collaboration and trust could achieve a common vision. Bush et al. (2010) explained that the tendency of a leader to focus on the development and maintenance of a vision alone is not enough to promote effectiveness. It has also been 
asserted that if a leader focuses entirely on vision, it is likely to result in failure of leadership instead of effective leadership. Presidents show how people behave towards one another by having strong values and beliefs of how the cooperation should achieve the shared vision. For example, President two stated, "Trust comes with building your relationship and listening and talking and having respect for everyone's ideas and getting people involved in the process of vision making."

A sound relationship that involves trust helps everyone collaborate around the main vision easily. University presidents behave in ways, which are consistent with the policies and vision of the university. They also serve as a role model for the staff, faculty and students. According to, Brumfield and Miller (2006) deemed possession of interpersonal skills to interact effectively with internal and external stakeholders and having a vision to perceive as well as share that perception with others are regarded as key features of effective leaders in academic institutions (See Figure 5.1).

A strategic approach that presidents used helps to better explain the plan to the followers and helps absolve the challenges by actively approaching the solution. Ramsden (1998) has emphasized the role of a leader as a strategic planner. To motivate followers, presidents provide them with a sense of direction and also involve rewards and incentives that can be a source of attraction for them (Pounder, 2001). The appreciation and encouragement also become a source of positive reinforcement for their followers, which motivate them to repeat positive actions in the future as well.

An example explains the PROCESS of the five practices: first, to enable others to act, a leader must act in accordance with vision. 

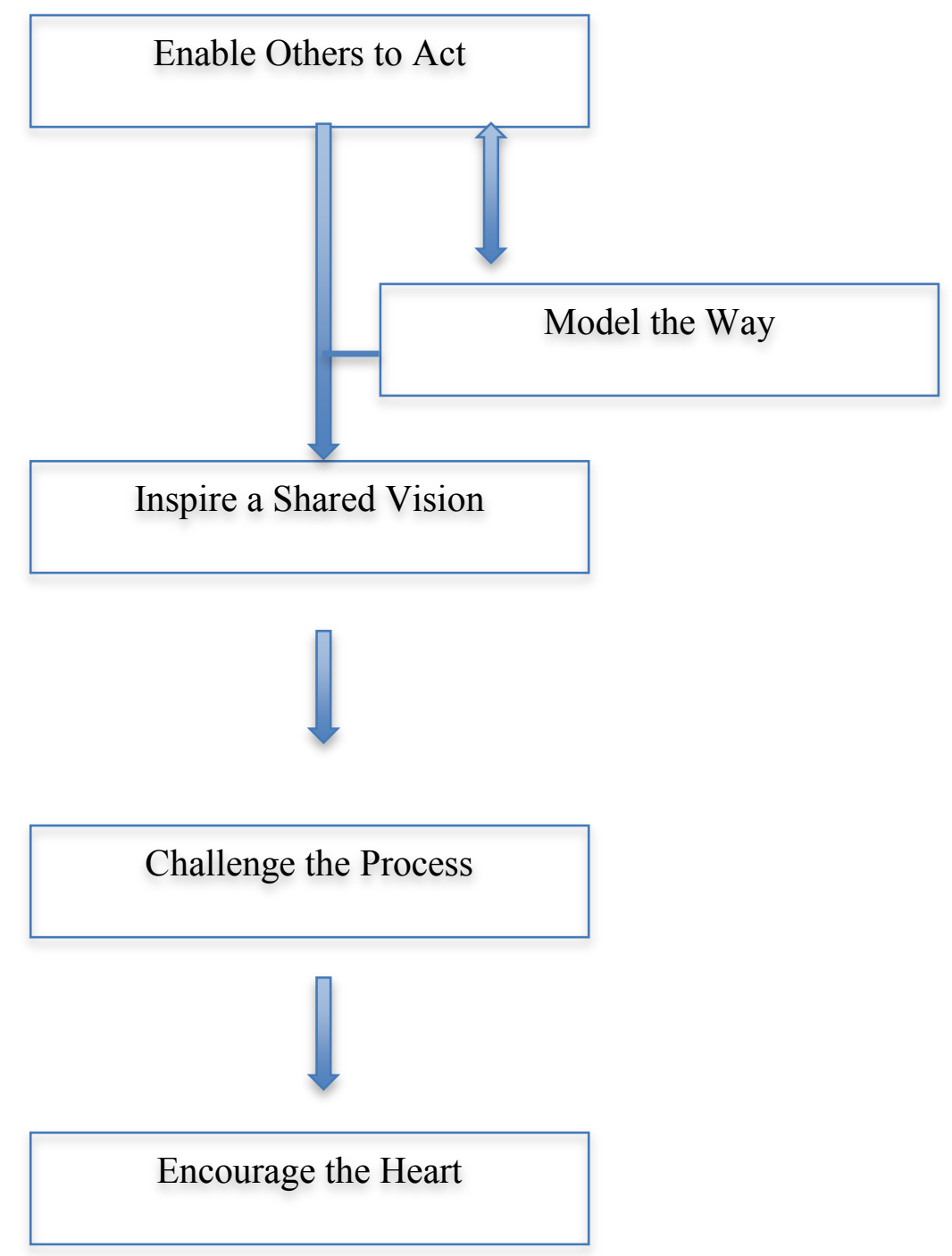

Figure 5.1. Leadership Practices Model of Presidents of Land-Grant Universities

By modeling the behavior that the leader wishes the followers to act, the followers gain a better understanding by having a visual representation of the task. The whole point is to illustrate that a 
leader must be a follower first and act as he or she believes. In part, it is gaining the trust of the followers by showing that the leader would do what he or she told them to do. It is the process of building a relationship between leader and followers, and by doing so, enabling the follower to act. Therefore, the similarities between the presidents included the importance of listening to the followers' input and actively including them within the plan. By including them, followers feel as if they are an important aspect, and this motivates them to proceed with the goal.

University presidents were aware of the importance of each practice that makes them an effective leader and enhances the organizational performance. They engaged highly in all five leadership practices that were discussed by Kouzes and Posner (2002). Also, "Enabling Others to Act" is the ultimate means to reach the goal in conjunction with "Modeling the Way." In sum, the leadership practice model is a "PROCESS" in which all five practices work together to achieve the ultimate goal. This is how the presidents of land-grant universities described their leadership practices.

\section{Implications from the Study}

This study examined the leadership practices of presidents at land-grant universities using a self-perspective. The study can help current university presidents in understanding the process that leaders go through to be successful in administrating their organization. This study broadens the understanding of all stakeholders, particularly university presidents, to see that leadership practices play a critical role in organizational performance. The presidents in land-grant universities can identify how the leadership framework of Kouzes and Posner (2002) can be applied to enhance their level of effectiveness as a leader. In addition to this, the positive effects of five practices on organization can encourage the university presidents to facilitate the faculty and staff to play a role in success of academic institutions. The university presidents can also 
identify the areas where they need to bring improvement to ensure that the staff and students are provided with adequate guidance and support. Moreover, the development and implementation of a strategic plan of action of land-grant university is dependent on the leadership skills of the university presidents. Therefore, the dissertation can provide invaluable information about the role leadership practices can play in strategy implementation.

Furthermore, the study serves to add to the existing literature review on leadership, specifically leadership in organizations with of limited resources such as public universities. Also, it could further be used to develop the curricula of administration leadership programs and get more emphasis on the important role of leaders in "Enabling Others to Act," the first factor to enhance the leadership effectiveness and success of the organization. However, the leadership practice model developed in this study cannot replace the existing knowledge of literature on leadership, but rather supplement. It is important to understand the necessity of offering tangible and intangible rewards to the staff and faculty for their achievements. The reinforcement of desirable behavior results in reoccurrence of such behaviors. Furthermore, appreciation of creativity can also be a key area of consideration in enabling others to act. Presidents can faculty the faculty to use innovation for carrying out their responsibilities. University presidents need to support the personnel in brining creative solutions to the problems as well. The study also carries implications for government and state officials who can understand the importance of leadership skills of university presidents. They can also identify the level of competence of a leader on the basis of five practices of leadership.

Higher education institutions are exposed to changing external environment, as officials are well aware of the need to adapt to the changing environment. The study can help them in understanding necessary leadership skills through which a university president can support HEIs 
during times of change. The research can further provide knowledge to university presidents that how the staff and faculty can be supported in adjusting to the changes. The administration of the universities can also benefit from the study as they can also adopt the five practices of leadership in their dealing with other people. Therefore the leader can create an environment that supports individual as well as organizational growth and development in the university.

To gain more insight into the leadership practices of university presidents, a replication of this study can be conducted using self and observer perceptions of university presidents. LPI survey and interview of university presidents and followers can be conducted to identify the differences in the perception of leaders and followers for leadership practices. The university presidents can be asked to fill LPI survey keeping in view their leadership practices. The followers can fill the LPI survey keeping the president's leadership practices in view. Thus, it will provide the perspective of university president and followers about the capability of the president for being a leader. This type of study would be of interest to the presidents, who can benefit by seeing how their followers perceive them.

Moreover, the position of the university president is the most critical leadership role in the university system. It is important to understand the role of leaders in higher education and expand our knowledge of the presidency leadership. This study was limited to the number of participants to meet the objective of the study. Further study could use a larger sample and include all presidents at public universities or could compare the leadership practices of university presidents at public and private universities to see if there is a unique pattern of leadership practices between the two samples or to identify the differences between the two samples. Such a study would give a better picture of the leadership practices of university presidents. Moreover, researchers need to consider the difficulty of getting adequate responses 
from university presidents, who have many responsibilities and travel often throughout the year. A large sample could remove this problem. 


\section{References}

Aagard, K. A. (2011). Leadership in nonprofit organizations: A reference handbook, (2). USA: SAGE Publications, Inc.

Aaker, S. (2003). Leadership styles of executive female administrators in Tennessee community colleges. Tennessee State University. ProQuest Dissertations and Theses, 140-140. Retrieved from: http://search.proquest.com/docview/305243070?accountid=2837

Altbach, P. G., Gumport, P. J. \& Berdahl, R. O. (2011). American higher education in the twenty-first century: Social, political and economic challenges. USA. The John Hopkins University Press.

American Institute of Higher Education, (2011). Influences of instructional leadership, transformational leadership and the mediating effects of self-efficacy on the student's achievement. The $6^{\text {th }}$ International Conference, 4 (1).

Anderson, D. (2004). Vocational advisory committee chair leadership practices: A comparison of chairs' and members' perceptions at selected New Mexico community colleges. New Mexico State University. Pro Quest Dissertations and Theses, 135. Retrieved from: http://search.proquest.com/docview/305165412?accountid=2837

Arx, J. V. (2009). What does a president do? Retrieved from: http://blog.ctnews.com/vonarx/2009/09/04/what-does-a-president-do/

Barman, P. K. (2009). Leadership management: Achieving breakthrough. Global India Publications.

Barnham, C. (2012). Separating methodologies. International Journal Of Market Research, $54(6), 736-738$ 
Barrett, J. R. (2007). The researcher as instrument: Learning to conduct qualitative research through analyzing and interpreting a choral rehearsal. Music Education Research, 9(3), 417-433.

Bauer, M. (1994). Are the leadership practices of college presidents in the northeast distinct from those of leaders of business and industry? University of New Haven. Pro Quest Dissertations and Theses, 152-152. Retrieved from: http://search.proquest.com/docview/304184602? accountid=2837

Bensimon, E. M. (1989). The meaning of "good presidential leadership": A frame analysis. Review of Higher Education, 12(2), 107-23.

Bess, J. L \& Dee, J. R. (2008). Understanding college and university organization: Theories for effective policy and practice. V2, Dynamics of the system. Sterling, VA: Stylus.

Bok, D. C. (1982). Beyond the ivory tower: Social responsibilities of the modern university. UK: Harvard University Press.

Bolman, L. G. \& Deal, T. E. (1990). Leadership orientations (self). Brookline, MA: Leadership Frameworks.

Bowen, H. R. (1997). Investment in learning: The individual and social value of American higher education. London. UK: The John Hopkins Press Limited.

Bretz, F., Hothorn, T. \& Westfall, P. (2011). Multiple comparisons using R. USA: Taylor \& Francis Group, LLC.

Brinkman, P., \& Morgan, A. (1995). The future of higher education. New Directions for Institutional Research, 85, 9-19.

Brown, L. M. (2001). Leading leadership development in universities: A personal story. Journal of Management Inquiry, 10 (4), 312-323. 
Brown, D. G. (2006). University presidents as moral leaders. USA: Praeger Publishers.

Brown, E. D. (2010). Four-year historically black college and university president: An examination of leadership styles, values, and attributes. Alabama State University. ProQuest Dissertations and Theses, p.182. Retrieved from: http://search.proquest.com/docview/897667651?accountid=2837

Brumfield, R., \& Miller, M. T. (2006). The leadership needs of college presidents: A practical question and response. John Ben Shepperd Journal of Practical Leadership, 1(1), 9-17.

Bush, T., Bell, L. \& Middlewood, D. (2010). The principles of educational leadership and management. USA: SAGE Publications, Inc.

Carless, S. A. (2001). Assessing the discriminate validity of the leadership practices inventory. Journal of Occupational and Organizational Psychology, 74(2), 233-239

Carter, J. C. (2012). Quality Cutting: Perceived faculty and staff effects of state budget cuts on institutional quality. Public Organiz Rev, 12, 41-56

Castro, J. R. (. (2003). Effective leadership among academic deans: An exploration of the relationship between emotional competence and leadership effectiveness. University of Missouri - Columbia). ProQuest Dissertations and Theses, 123-123 p. Retrieved from http://search.proquest.com/docview/305309778?accountid=2837

Chang, C. (2005). Effects of transformational leadership on followers' feedback seeking, feedback preference, and reactions to feedback through cognitive and motivational processes. The University of Akron. ProQuest Dissertations and Theses, 194-194 p. Retrieved from http://search.proquest.com/docview/305021377?accountid=2837

Christ, W. G. (1998). Leadership in times of change: A handbook for communication and media administrators. USA: Routledge. 
Cross, C.F. (1999). Justin smith morrill: Father of the land-grant colleges. East Lansing, MI: Michigan State University. 159 pp.

Daft, R. L. \& Lane, P.G. (2008). The leadership experience. USA: Thomson Southwestern.

Dennis, R. S \& Bocarnea, M. (2005). Development of the servant leadership assessment Instrument. Leadership \& Organization Development Journal, 26 (8), 600 - 615

Drumm, M. D. (2011). University presidents' leadership frame and giving. Tarleton State University. ProQuest Dissertations and Theses, 171. Retrieved from: http://search.proquest.com/docview/879422096?accountid=2837

Du Plessis, S. B. (2008). Leadership practices of women superintendents: A qualitative study. Virginia Polytechnic Institute and State University. ProQuest Dissertations and Theses, 131. Retrieved from: http://search.proquest.com/docview/1030959659?accountid=2837

Dunn, D.D., Gibson, F.K. \& Whorton, J. W. (1985). The university president as pragmatist: An investigation of priorities. Research in Higher Education, 23 (1), 96-106.

Eckel, P.D., (2002). Academic leadership. In Forest, J. F., and Kinser, K.(eds.)(2002). Higher Education in the United States: An Encyclopedia. Santa Barbara, CA: ABC-CLIO.

Eden, D., \& Shani, A. B. (1982). Pygmalion goes to boot camp: Expectancy, leadership, and trainee performance. Journal of Applied Psychology, 67(2), 194-199.

Education Encyclopedia (2013). Land grant colleges and universities. Retrieved from: http://education.stateuniversity.com/pages/2152/Land-Grant-Colleges-Universities.html

Englehardt, E. E., Pritchard, M.S., Romesburg, K. D. \& Schrag, B. E. (2009). The ethical challenges of academic administration. USA: Springer.

Fisher, J. L. (1991). The board and the president. New York, NY: American Council on Education and Macmillan Publishing Co. 
Fullan, M. \& Scott, G. (2009). Turnaround leadership for higher education. USA: John Wiley \& Sons, Inc.

Geiger, R. L. (2005). History of higher education annual 2003-2004. USA: Transaction Publishers, 23.

Goodman, P. (2012). Prepare for the chancellor's greatest gamble of all. Financial Times. p. 13. Retrieved from: http://search.proquest.com/docview/1017880160?accountid=2837

Gilley, J. W., Fulmer, K. A., \& Reithlingshoerfer, S. J. (1986). Searching for academic excellence: Twenty colleges and universities on the move and heir leaders. New York: American Council on Education and Macmillan Publishing Company.

Green, K. C. (2008). Community colleges and the economic downturn. The Campus Computing Project. Retrieved from: http://www.league.org/2/collaboration/blog/files/leadership_03-2009.pdf

Hempowicz, C. D. (2010). Transformational leadership characteristics of college and university presidents of private title III and title V-eligible institutions. University of Bridgeport. ProQuest Dissertations and Theses, 247. Retrieved from: http://search.proquest.com/docview/878892691?accountid=2837

Higher Education Resources Hub (2008). A listing of all land-grant institutions. Retrieved from: http://www.higher-ed.org/resources/land_grant_colleges.htm

Ihedigbo, C. E. (2012). Leadership preparation factors common in outstanding historically black colleges and universities member institution presidents. Capella University. ProQuest Dissertations and Theses, 138. Retrieved from: http://search.proquest.com/docview/1031210431?accountid=2837 
Iskander, M. (2008). Innovative techniques in instruction technology, E-learning, E-assessment and education. USA: Springer.

Johnson, D. W. (2009). The laws that shaped America: Fifteen Acts of Congress and their lasting impact. USA: Routledge.

Junarso, T. (2009). Leadership Greatness: Best Practices to Become a Great Leader. USA: iUniverse.

Kerr, C. (1984). Presidents make a difference. Report of the commission on strengthening presidential leadership. Washington, DC: Association of Governing Boards of Universities and Colleges.

Knuth, R. K. \& Banks, P. A. (2006). The essential leadership model. NASSP Bulletin, 90 (1), 418.

Kouzes, J. \& Posner, B. (2002). The leadership challenge ( $3^{\text {rd }}$ ed.) John Willey and Sons, Inc.

Kouzes, J. \& Posner, B. (2002). The leadership practices inventory: Theory and evidence behind the five practices of exemplary leaders. Retrieved from: http://media.wiley.com/assets/463/74/lc_jb_appendix.pdf

Kouzes, J. \& Posner, B. (2003). The five practices of exemplary leadership. San Francisco: Pfeiffer.

Kouzes, J. \& Posner, B. (2012). Percentile ranking. The leadership challenge Website. Retrieved from: http://www.leadershipchallenge.com/UserFiles/PercentileRankingFINAL012012.pdf

Kramer, G. L. \& Swing, R. L. (2010). Higher education assessments: Leadership matters. UK: Rowman \& Littlefield Publishers, Inc. 
Krill, T. L., Carter, R. I. \& Williams, D. L. (1997). An exploration of the leadership practice enabling others to act: A case study. Journal of Agricultural Education, 38 (4), 42-49. Land Grant University (n.d). Retrieved from: http://dictionary.reference.com/browse/landgrant+university

Langone, C. A. (2006). Promoting student engagement through an academic leadership certificate program. Journal of Higher Education Outreach and Engagement, 11(1), 105117.

Lathbury, R. \& Phillips, J. \& Anesko, M. \& Meyers, K. (2010). Realism and regionalism: (18601910): Backgrounds to American literature. Chelsea House Publications (2 nd ed.).

Leadership Terms and Concepts (n.d). Glossary. Retrieved from: http://garybclayton.com/leadership/leadership-glossary/

London, M. (1995). Achieving performance excellence in university administration: A team approach to organizational change and employee development. Praeger Publishers.

Lorange, P. (2002). New vision for managing education: leadership challenges. Elsevier Science Ltd. UK.

Lincoln, Y. S. \& Guba, E. G. (1985). Naturalistic inquiry. Newbury Park: Sage.

Madsen, S. R. (2008). On becoming a woman leader: Learning from the experiences of university presidents. Jossey-Bass, (124)

Marris, E. (2010). US students pay for downturn. Nature. 465, 678-679.

Mathern, D. (1998). Leadership strategies of American university presidents: A leadership model analysis. Bowling Green State University, ProQuest, UMI Dissertations Publishing, 99. 
Maykut, P. \& Morehouse, R. (1994). Beginning qualitative research: A Philosophical and Practical Guide. London: Falmer Press.

McCaffery, P. (2010). The higher education manager's handbook: Effective leadership and management in colleges and universities. USA: Routledge.

McClure, A. F., Chrisman, J. R. \& Mock, P. (1985). Education for work: The historical evolution of vocational and distributive education in America. UK: Associated University Presses, Inc.

McMurray, A. P. (2010). Exploring the essence of relational leadership in the role of university president. Gonzaga University. ProQuest Dissertations and Theses, 269. Retrieved from http://search.proquest.com/docview/288309193?accountid=283

Middlebrooks, A. \& Allen, S. J. (2009). Editors' introduction: The education of leadership. Journal of Leadership Education, 8 (1), 8-22.

Mills, R. W. (2004). University presidents and their leadership: Crisis scenarios at institutions of higher education. Oklahoma State University. ProQuest Dissertations and Theses, 211211 p. Retrieved from: http://search.proquest.com/docview/305086059?accountid=2837

Morrill Act (n.d). Retrieved from: http://dictionary.reference.com/browse/morrill+act

Morrill Act of 1890. (n.d). Retrieved from http://www.superglossary.com/Definition/Agriculture/Morrill_Act_Of_1890.html National Research Council. (1995). Colleges of agriculture at the land grant universities: A profile. USA: National Academy of Sciences.

Nehls, K. (2011). Leadership transitions during fundraising campaigns. Innovative Higher Education, 8, 198-218. 
Nicholson, W. D. (2007). Leading where it counts: An investigation of the leadership styles and behaviors that define college and university presidents as successful fundraisers. International Journal of Educational Advancement, 7, 256-270.

Northouse, P. G. (2010). Leadership: Theory \& practice $\left(5^{\text {th }}\right.$ ed). USA: SAGE Publications, Inc.

Oliver, S. W. (2001). The leadership practices of chief student affairs officers in Texas: A comparative analysis. Texas A\&M University. ProQuest Dissertations and Theses, 141141 p. Retrieved from: http://search.proquest.com/docview/275908985?accountid=2837

Orman, P. B. (2002). Footprints to the academic deanship: Women, generative leadership, and power. University of Colorado at Denver. ProQuest Dissertations and Theses, 288-288. Retrieved from: http://search.proquest.com/docview/305447705?accountid=2837

Padilla, A. (2005). Portraits in leadership: Six extraordinary university presidents. USA: Praeger Publishers.

Parolini, J., Patterson, K. \& Winston, B. (2009). Distinguishing between transformational and servant leadership. Leadership \& Organization Development Journal, 30 (3), 274 - 291.

Parse, R (2009). Mixed methods or mixing meanings in research? Nursing Science Quarterly, 22 (2), p.101

Paul, R. (2011). Leadership under fire: The challenging role of the Canadian university presidents. Montreal and Kingston: McGill-Queen’s University Press.

Plowman, R. J. (1991). Perceptions of presidential leadership behavior and institutional environment by presidents and vice presidents of selected four-year colleges and universities in Florida. The University of Mississippi. ProQuest Dissertations and 
Theses, 223-223. Retrieved from:

http://search.proquest.com/docview/303923161?accountid=2837

Portney, P. (2011). The leadership vacuum in higher education. Washington Post. Retrieved from : http://articles.washingtonpost.com/2011-10-31/national/35279954_1_universitypresidents-higher-education-state-universities

Pounder, J. S. (2001). New leadership and university organizational effectiveness: Exploring the relationship. Leadership \& Organization Development Journal, 22(6), 281-290.

Ramsden, P. (1998). Learning to lead in higher education. London: Routledge.

Rauner, F. \& Maclean, R. (2008). International handbook of education for the changing world of work. Alix Wurdak.

Investopedia (n.d.). Definition of 'recession'. Retrieved from: http://www.investopedia.com/terms/r/recession.asp\#axzz1Yygh2edQ

Rost, J.C. (1993). Leadership development in the new millennium. The Journal of Leadership Studies. 91-110

Rozeboom, D. J. (2008). Self-report and direct observer's perceived leadership practices of chief student affairs officers in selected institutions of higher education in the United States. PhD dissertation. Texas A\&M University. 179

Russell, R. F. \& Stone, A. G. (2002). A review of servant leadership attributes: Developing a practical model. Leadership \& Organization Development Journal, 23 (3), 145-157.

Safrit, R. D., Gamble, C., Gliem, J. A and Gliem, R. R. (2004). Leadership practices of formal and informal leaders in the ohio state university college of food, agricultural and environmental sciences. The 20th Annual Conference. Dublin, Ireland. Retrieved from http://www.aiaee.org/attachments/article/1064/013.pdf 
Savin-Baden, M. (2000). Problem-based learning in higher education: Untold stories. UK: Open University Press.

Shapiro, J. P. \& Stefkovich, J. A. (2011). Ethical leadership and decision making in education: Applying theoretical perspectives to complex dilemmas. USA: Routledge.

Sherwood, J. E. (2004). The role of the land-grant institution in the $21^{\text {st }}$ century. Research and Occasional Paper Series: CSHE. 6 (4), 1-8

Shields, C. M. (2006). Creating spaces for value-based conversations: The role of school leaders in the 21st century. International Studies in Educational Administration 34(2), 62-81.

Strang, K. D. (2005). Examining effective and ineffective transformational project leadership. Team Performance Management, 11 (3/4),68 - 103.

Stern, A. (2008). US colleges punished by financial crisis. Reuters. Retrieved from http://www.reuters.com/article/2008/10/30/us-financial-collegesidUSTRE49T02E20081030

Taylor, T., Martin, B. M., Hutchinson, S., \& Jinks, M. (2007). Examination of leadership practices of principals identified as servant leaders. International Journal of Leadership in Education, 10 (4), 401-419

Teddlie, C. \& Fen Yu (2007). Mixed methods sampling: A typology with examples. Journal of Mixed Methods Research, 1(1) p 77-100

United Methodist Communication (2009). Response rates and surveying techniques: Tips to enhance survey respondent participations. Survey Monkey, Retrieved from: http://www.umcom.org/atf/cf/\%7B60C02017-4F6A-4F3B-883A4AFAECE1182F\%7D/RESPONSE_RATES.PDF 
Valenzuela, D. \& Shrivastava, P. (2008). Interview a method of qualitative research. Retrieved from: http://www.public.asu.edu/ kroel/www500/Interview\%20Fri.pdf

Vernon, M. C., \& Byrd, J. W. (1996). Leadership in the 21st century: New roles for federal probation and pretrial services chiefs. Federal Probation, 60(1), 21.

Walker, D. E. (1981). The president as ethical leader of the campus. New Directions for Higher Education, (33), 15-27.

Weaver, N. R. (2005). Presidential leadership: A phenomenological study of the leadership experience of oklahoma's regional university presidents. The University of Oklahoma). ProQuest Dissertations and Theses, 148-148

Winston, B. E., \& Patterson, K. (2006). An integrative definition of leadership. International Journal of Leadership Studies, 1 (2). Retrieved from: http://www.regent.edu/acad/global/publications/ijls/new/volliss2/winston_patterson.doc/ winston_patterson.pdf

Wishart, D. J. (2004). Encyclopedia of the Great Plains. University of Nebraska Press.

Woods, P. (2004). Democratic leadership: drawing distinctions with distributed leadership. International Journal of Leadership in Education, 7 (1), 3-26. 


\section{Appendix A}

\section{A List of All Land-Grant Universities}

\section{N Land-grant University}

$1 \quad$ Alabama A\&M University

2 Auburn University

3 Tuskegee University

$4 \quad$ University of Alaska, Fairbanks

5 University of Arizona

6 University of Arkansas Pine Bluff

7 University of California-Berkeley

8 Colorado State University

9 University of Connecticut

10 University of Delaware

11 University of the District of Columbia

12 Florida A\&M University

13 University of Florida

14 University of Georgia

15 University of Guam

16 University of Hawaii

17 University of Idaho

18 University of Illinois

19 Purdue University

20 Iowa State University 


\section{N Land-grant University}

21 Kansas State University

22 Kentucky State University

23 University of Kentucky

24 Louisiana State University

25 Southern University

26 University of Maine

27 University of Maryland-College Park

28 Massachusetts Institute of Technology-University of Massachusetts

29 Michigan State University

30 University of Minnesota

31 Alcorn State University

32 Mississippi State University

33 Lincoln University

34 University of Missouri

35 Montana State University-Bozeman

36 University of Nebraska

37 University of Nevada, Reno

38 University of New Hampshire

39 Rutgers-the State University of New Jersey

40 New Mexico State University

41 Cornell University 


\section{N Land-grant University}

42 North Carolina A\&T State University

43 North Carolina State University

44 North Dakota State University

45 Ohio State University

46 Langston University

47 Oklahoma State University

48 Oregon State University

49 Pennsylvania State University

$50 \quad$ University of Rhode Island

51 Clemson University

52 South Carolina State University

53 South Dakota State University

54 Tennessee State University

55 University of Tennessee

56 Prairie View A\&M University

57 Texas A\&M University

58 Utah State University

59 University of Vermont

60 University of the Virginia Island

61 Virginia Polytechnic Institute \& State University-Virginia State University

62 Washington State University 


\section{N Land-grant University}

63 West Virginia University

64 University of Wisconsin-Madison

65 University of Wyoming

Note: The table presents the names of all land-grant Universities adapted from Higher

Education Resource Hub (2008). Available on the Internet at:

http://www.higher-ed.org/resources/land_grant_colleges.htm 


\section{Appendix B}

\section{Leadership Practices Inventory Individual Survey}

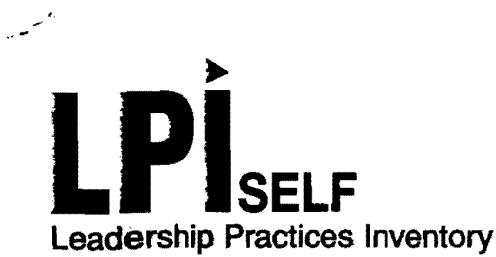

by JAMES M. KOUZES

\& BARRY Z. POSNER

\section{INSTRUCTIONS}

Write your name in the space provided at the top of the next page. Below your name, you will find thity statements describing various leadership behaviors. Please read each statement carefully, and using the RATING SCALE on the right, ask yourself:

\section{"How frequently do I engage in the behavior described?"}

- Be realistic about the extent to which you actually engage in the behavior.

- Be as honest and accurate as you can be.

- DO NOT answer in terms of how you would like to behave or in terms of how you think you should behave

- DO answer in terms of how you typically behave on most days, on most projects, and with most people.

- Be thoughtful about your responses. For example, giving yourself $10 \mathrm{~s}$ on all items is most likely not an accurate description of your behavior. Similarly, giving yourself all $1 \mathrm{~s}$ or all $5 \mathrm{~s}$ is most likely not an accurate description either. Most people will do some things more or less often than they do other things.

- If you feel that a statement does not apply to you, it's probably because you don't frequently engage in the behavior. In that case, assign a rating of 3 or lower.

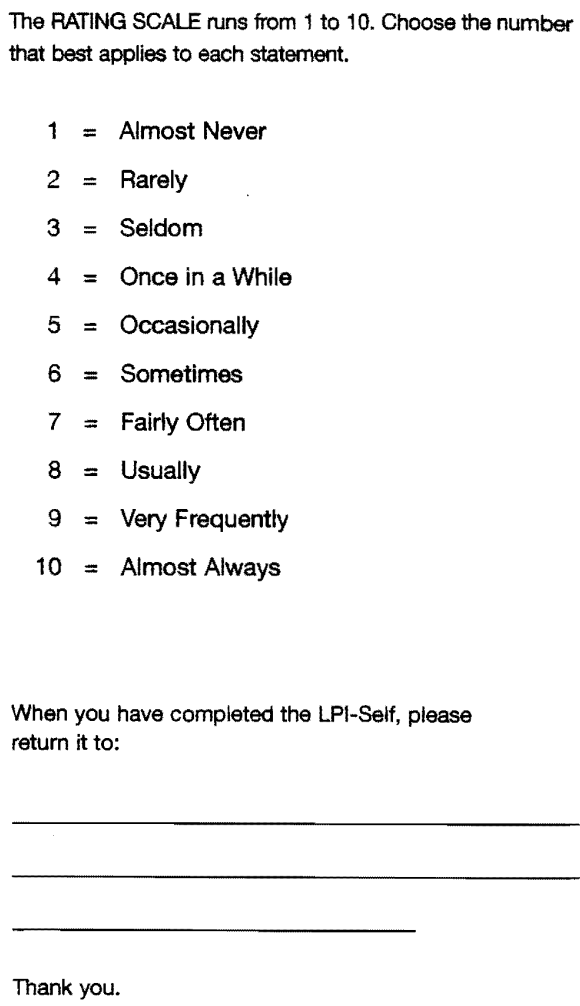

For each statement, decide on a response and then record the corresponding number in the box to the right of the statement. After you have responded to all thirty statements, go back through the LPI one more time to make sure you have responded to each statement. Every statement must have a rating. 
To what extent do you typically engage in the following behaviors? Choose the response number that best applies to each statement and record it in the box to the right of that statement.

1. I set a personal example of what I expect of others.

2. I talk about future trends that will influence how our work gets done.

3. I seek out challenging opportunities that test my own skills and abilities.

4. I develop cooperative relationships among the people I work with.

5. I praise people for a job well done.

6. I spend time and energy making certain that the people I work with adhere to the principles and standards we have agreed on.

7. I describe a compelling image of what our future could be like.

8. I challenge people to try out new and innovative ways to do their work.

9. I actively listen to diverse points of view.

10. I make it a point to let people know about my confidence in their abilities.

11. I follow through on the promises and commitments that I make.

12. I appeal to others to share an exciting dream of the future.

13. I search outside the formal boundaries of my organization for what we do.

14. I treat others with dignity and respect.

15. I make sure that people are creatively rewarded for their contributions to the success of our projects.

16. I ask for feedback on how my actions affect other people's performance.

17. I show others how their long-term interests can be realized by enlisting in a common vision.

18. I ask "What can we learn?" when things don't go as expected.

19. I support the decisions that people make on their own.

20. I publicly recognize people who exemplify commitment to shared values.

21. I build consensus around a common set of values for running our organization.

22. I paint the "big picture" of what we aspire to accomplish

23. I make certain that we set achievable goals, make concrete plans, and establish measurable milestones for the projects and programs that we work on.

24. I give people a great deal of freedom and choice in deciding how to do their work.

25. I find ways to celebrate accomplishments.

26. I am clear about my philosophy of leadership.

27. I speak with genuine conviction about the higher meaning and purpose of our work

28. I experiment and take risks, even when there is a chance of failure.

29. I ensure that people grow in their jobs by learning new skills and developing themselves.

30. I give the members of the team lots of appreciation and support for their contributions.

Copyright $\bigcirc 2003$ James M. Kouzes and Barry Z. Posner. All rights reserved. 


\title{
Appendix C
}

\section{President's Cover Letter}

To: [president email]

From: waldigri@yahoo.com

Date:

Subject: leadership Profile Inventory Survey Instrument

Body: Dear university President [last name],

| Leadership practices of university presidents are an important subject for academic leaders. However, no research has been done to evaluate leadership practices of university presidents of Land-grant University before. Therefore, I am requesting your | participation in an investigation of this essential roless of leadership. This study constitutes one of the requirements to complete my doctorate in the department of Educational Leadership Studies at West Virginia University.

The study aims to examine the leadership practices of university presidents of land-grant universities across the United States. The findings of this research will be essential in understanding the role of university presidents in HHigher Education. The Leadership Profile Inventory survey will take approximately 10-15 minutes of your time to complete. This research approved by the West Virginia University Institution Review Board (IRB). Hence, all names of participants and institutions will remain anonymous in the final research report. Your questionnaires will be identified by a code for follow-up purposes only. Your participation in this research is entirely voluntary.

For any questions regarding the study please Email me at waldigri@yahoo.com or you can contact my dissertation advisor Dr. Paul Chapman at paul.chapman@mail.wvu.edu

Thank you very much for your assistance.

\author{
Wafa Aldighrir \\ Doctoral Candidate \\ Educational Leadership \\ West Virginia University \\ Dr. Paul Chapman, Ph.D \\ 304-293-2174 \\ paul.chapman@mail.wvu.edu
}




\title{
Appendix D
}

\section{President's first reminder}

To: [president email]

From: waldigri@yahoo.com

Subject: leadership Profile Inventory Survey

Body: Dear university President [last name],

This is a courtesy reminder of the leadership profile inventory survey that was sent to you approximately two weeks ago. If you have already responded to the electronic survey, thank you very much. If not, I will appreciate your feedbacks, which is very important to the completion of my study.

For any questions regarding the study please Email me at waldigri@yahoo.com or you can contact my dissertation advisor Dr. Paul Chapman at paul.chapman@mail.wvu.edu

Thank you very much for your assistance.

\author{
Wafa Aldighrir \\ Doctoral Candidate \\ Educational Leadership \\ West Virginia University \\ Dr. Paul Chapman, Ph.D \\ 304-293-2174 \\ paul.chapman@mail.wvu.edu
}




\section{Appendix E}

\section{President's second reminder}

To: [president email]

From: waldigri@yahoo.com

Date:

Subject: Courtesy Reminder

Body: Dear university President [last name],

Thank you so much for taking your time to read my email. One month ago, I sent you a leadership Profile Inventory survey. I understand that this is the beginning of the semester and you must be very busy. However, I would really appreciate if you could spare at least 10-15 minutes of your time to respond to this survey, which is very important to the completion of my dissertation. The study will inform me, educational administrators, and other scholars in the leadership practices of university presidents of land-grant universities. Your response to this survey is truly appreciated.

For any questions regarding the study please Email me at waldigri@yahoo.com or you can contact my dissertation advisor Dr. Paul Chapman at paul.chapman@mail.wvu.edu

Thank you very much for your assistance.

Wafa Aldighrir

Doctoral Candidate

Educational Leadership

West Virginia University

Dr. Paul Chapman, Ph.D

304-293-2174

paul.chapman@mail.wvu.edu 


\section{Appendix F}

\section{Interview Request (First Email)}

To: [president email]

From: waldigri@yahoo.com

Date:

Subject: Interview Request

Body: Dear university President [last name],

Thank you for you participation in the Leadership Profile Inventory survey. After I analysis the survey results, an interview is request your participation to complete the second part of my study. The study aims to examine the leadership practices of university presidents of land-grant universities across the United States. The findings of this research will be essential in understanding the role of university presidents in Higher Education. The interview questions will take approximately one hour of your time to complete. All names of participants and institutions will remain anonymous in the final research report. Your questionnaires will be identified by a code for follow-up purposes only. Your participation in this research is entirely voluntary.

For any questions regarding the study please Email me at waldigri@yahoo.com or you can contact my dissertation advisor Dr. Paul Chapman at paul.chapman@mail.wvu.edu

Thank you very much for your assistance.

Wafa Aldighrir

Doctoral Candidate

Educational Leadership

West Virginia University

Dr. Paul Chapman, Ph.D

304-293-2174

paul.chapman@mail.wvu.edu 


\title{
Appendix $\mathbf{J}$
}

\section{Interview Request (Fellow-up Email)}

To: [president email]

From: waldigri@yahoo.com

Date:

Subject: Interview Request

Body: Dear university President [last name],

Thank you for your email. I would like to know the best time and day for you to do the interview.

The interview questions will take approximately one hour of your time to complete. Moreover, all names of participants and institutions will remain anonymous in the final research report. Your questionnaires will be identified by a code for follow-up purposes only. Your participation in this research is entirely voluntary.

For any questions regarding the study please Email me at waldigri@yahoo.com or you can contact my dissertation advisor Dr. Paul Chapman at Paul.chapman@mail.wvu.edu

Thank you very much for your assistance.

\author{
Wafa Aldighrir \\ Doctoral Candidate \\ Educational Leadership \\ West Virginia University \\ Dr. Paul Chapman, Ph.D \\ 304-293-2174 \\ paul.chapman@mail.wvu.edu
}

Note: Interview questions will attach with the email. 


\section{Appendix $\mathbf{H}$}

\section{Kouzes and Posner Leadership Profile Inventory Permission}

\section{JOSSEY-BASS}

An Imprint of WILEY

\section{News}

March 26, 2012

Wafa Aldighrir

806 Carmell Court

Morgantown, WV 26505

Dear Ms. Aldighrir:

Thank you for your request to use the Leadership Practices Inventory (LPI) in your dissertation. We are willing to allow you to reproduce the instrument in written form, as outlined in your request, at no charge. If you prefer to use our electronic distribution of the LPI (vs. making copies of the print materials) you will need to separately contact Lisa Shannon (Ishannon@wiley.com) directly for instructions and payment. Permission to use either the written or electronic versions requires the following agreement:

(1) That the LPI is used only for research purposes and is not sold or used in conjunction with any compensated management development activities;

(2) That copyright of the LPI, or any derivation of the instrument, is retained by Kouzes Posner International, and that the following copyright statement is included on all copies of the instrument;

"Copyright 82003 James M. Kouzes and Barry Z. Posner. All rights reserved. Used with permission",

(3) That one (1) electronic copy of your dissertation and one (1) copy of all papers, reports, articles, and the like which make use of the LPI data be sent promptly to our attention; and,

(4) That you agree to allow us to include an abstract of your study and any other published papers utilizing the LPI on our various websites.

If the terms outlined above are acceptable, would you indicate so by signing one (1) copy of this letter and returning it to me either via email or by post to; 1548 Camino Monde San Jose, CA 95125. Best wishes for every success with your research project.

Cordially,

Ellen Peterson

Permissions Editor

Epeterson4@gmail.com

I understand and agree to abide by these conditions:

(Signed)

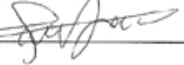

Date:

Expected Date of Completion is 